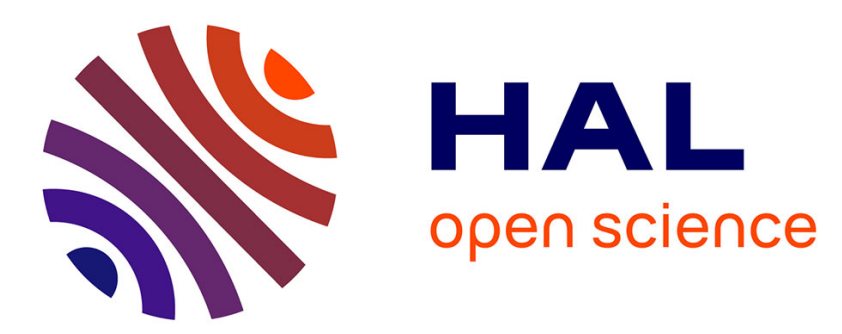

\title{
Lithosphere Destabilization and Small-Scale Convection Constrained From Geophysical Data and Analogical Models
}

\author{
C. Adam, Valérie Vidal, B. Pandit, A. Davaille, P. D Kempton
}

\section{- To cite this version:}

C. Adam, Valérie Vidal, B. Pandit, A. Davaille, P. D Kempton. Lithosphere Destabilization and Small-Scale Convection Constrained From Geophysical Data and Analogical Models. Geochemistry, Geophysics, Geosystems, 2021, 22 (3), pp.e2020GC009462. 10.1029/2020GC009462 hal-03343689

\author{
HAL Id: hal-03343689 \\ https://hal.science/hal-03343689
}

Submitted on 14 Sep 2021

HAL is a multi-disciplinary open access archive for the deposit and dissemination of scientific research documents, whether they are published or not. The documents may come from teaching and research institutions in France or abroad, or from public or private research centers.
L'archive ouverte pluridisciplinaire HAL, est destinée au dépôt et à la diffusion de documents scientifiques de niveau recherche, publiés ou non, émanant des établissements d'enseignement et de recherche français ou étrangers, des laboratoires publics ou privés. 
Lithosphere destabilization and small-scale convection constrained from geophysical data and analogical models

\author{
C. Adam, V. Vidal, B. Pandit, A. Davaille, and P.D. Kempton
}

Abstract

The destabilization of oceanic lithosphere by small scale convection at its base is important for providing a holistic picture of mantle/lithosphere coupling. We use three highly resolved tomography models to characterize the base of the oceanic lithosphere in the Pacific Ocean. Regions associated with abnormally thick lithosphere are associated with seafloor older than 100 $\mathrm{Ma}$ and are elongated parallel to the direction of present-day Pacific plate motion. They are correlated with bathymetric lows and negative geoid anomalies (for $1=10-39$ and l=14-39), which can be accounted for by dynamic topography. They do not correlate with volcanic features. We interpret these regions of thickened lithosphere as evidence for sites of lithospheric instabilities where denser lithosphere detaches and sinks into underlying mantle. To understand the phenomena at the origin of these lithospheric 'drips', we performed laboratory experiments. Fluids with different properties are heated from one side to generate a large-scale convection and cooled from the top. This configuration results in the generation of small-scale convection at the base of the upper cold thermal boundary layer. The experimental results show the existence of two possible structures: instabilities organized into longitudinal rolls, aligned in the direction of the large-scale motion and 3D, time-dependent cold plumes that drip from the base of the lithosphere and are sheared away by the large-scale flow. The 3D plume morphology is similar to what we observe in tomography models. This provides insights into the phenomenology at the origin of the lithospheric drips observed in the geophysical data.

\title{
1. Introduction
}

Most of the heat out of the Earth's mantle is transported by large-scale convection, which drives the motion of tectonic plates. The secondary convection or small-scale convection (SSC) occurring at the base of the lithosphere has been invoked as a mechanism of heat transfer from the mantle to the surface (Parsons and McKenzie, 1978; Davaille and Jaupart, 1994; Huang and Zhong, 2005), and also defines the coupling between mantle and lithosphere. The existence of SSC has been proposed to account for observed geophysical data, such as the seafloor depth, which reflects the thermal subsidence of the oceanic lithosphere.

After its creation at mid-oceanic ridges, oceanic lithosphere thickens and, as rock density increases due to cooling, the lithosphere slowly sinks into the underlying mantle. Therefore, seafloor depth scales as the square root of age for young ages. For old ages $(\sim>70 \mathrm{Ma})$, the observed seafloor depth is shallower than the model predictions (Sclater, 1975; Parsons and Sclater, 1977; Stein and Stein, 1992). This departure from predicted seafloor depth has been attributed to additional heat supplied to the base of the old oceanic lithosphere. Several hypotheses have been proposed to account for the additional heat supply. Among them, heat supply through secondary convection is the most widely accepted hypothesis (Parsons and McKenzie, 1978; Huang and Zhong, 2005). Its origin is commonly explained as follows. The lithosphere can be seen as the thermal boundary 
layer of the convective mantle; this thermal boundary layer thickens with increasing distance from mid-oceanic ridges. At sufficiently large distances, i.e. for sufficiently thick lithosphere, it may become gravitationally unstable and destabilize or delaminate (Parsons and McKenzie, 1978; Houseman and McKenzie, 1982; Fleitout and Yuen, 1984; Zaranek and Parmentier, 2004). By doing so, the plate becomes locally thinner and hot underlying mantle upwells to fill the gap, thus bringing supplementary heat to the base of the lithosphere, which accounts for the observed flattening.

Other explanations for the additional heat supply include mantle plumes (Schroeder, 1984; Davies, 1988) and the combination of small-scale convection and internal heating (Huang and Zhong, 2005; Korenaga, 2015). Huang and Zhong (2005) focus on steady-state models, while Korenaga (2015) argues that transient models are more pertinent. For some authors, there is no departure from the half-space model (Marty and Cazenave, 1989; Heestand and Crough, 1981; Schroeder, 1984; Korenaga and Korenaga 2008). Old seafloor is covered by numerous volcanic features such as hotspot chains, isolated seamounts, and oceanic plateaus, which potentially obscure the "normal" structure of the lithosphere. Flattening might then be seen in only a small fraction of the global data (Korenaga and Korenaga, 2008).

Other data, such as the geoid and heat flow are also often used to constrain SSC. The half space model, according to which the lithosphere thickness scales as the square root of age all along the plate (Davis and Lister, 1974), systematically overestimates geoid anomalies for old ages (Parsons and Sclater, 1977; Sandwell and Schubert, 1980; Renkin and Scalter, 1988; Stein and Stein, 1992). For DeLaughter el al. (1999), introducing an additional heat supply at the base of the lithosphere (the plate model), provides a better explanation for the observed geoid. However, the difference between the half space and plate models in the geoid signature is difficult to interpret (Hager, 1983; Korenaga and Korenaga, 2008). Using the geoid to constrain lithospheric plate cooling may be controversial (Korenaga and Korenaga, 2008). According to Davaille and Jaupart (1994), heat flow data would be more valuable than depth and geoid data, as they are less sensitive to the deep thermal structure of the mantle. The half space model underestimates the heat flow for ages $>110$ Ma (Davis et al., 1984; Lister et al., 1990). This has been interpreted as heat being supplied to the base of the lithosphere by SSC (Parsons and McKenzie, 1978; Davaille and Jaupart, 1994). For other authors, the observed heat flow data do not require the existence of secondary convection (Korenaga and Korenaga, 2008). Studies also show that heat flow is rather insensitive to sublithospheric processes (Korenaga and Jordan, 2002; Korenaga, 2009).

The existence of SSC from geophysical data is then a debated topic. However, even authors who do not think that SSC is required to account for observed seafloor depth do not rule out the existence of secondary mantle convections. Korenaga and Jordan, (2002) and Korenaga (2015), acknowledge that SSC is dynamically feasible beneath oceanic lithosphere given our understanding of mantle rheology (Karato and Wu, 1993; Hirth and Kohlstedt, 2003). As Davaille and Jaupart (1994) point out, "small scale convection is a likely consequence of cooling at the top of the mantle, away from a mid-oceanic ridge, and is a natural feature of convection in fluids with temperature dependent viscosity (Stengel et al., 1982; Richter et al., 1983; Fleitout and Yuen, 1984; Jaupart and Parsons, 1985; White, 1988; Ogawa et al., 1991)”.

Since the 1980's, small-scale convection has been widely studied through analytical, numerical, 
and analog experiments (Richter et al., 1983; Fleitout and Yuen, 1984; Davaille and Jaupart, 1993; 1994; Marquart et al., 1999; Dumoulin et al., 2001; among numerous others). In spite of the apparent consensus about the importance of small-scale convection, its characteristics are still debated. It is often described as longitudinal convection rolls or Richter rolls (Richter and Parsons, 1975), aligned along the direction of the plate motion (e.g., Parsons and McKenzie, 1978; Buck and Parmentier, 1986; Davaille and Jaupart, 1994; Korenaga and Jordan, 2003; 2004). However, the characteristics of these rolls vary depending on the models. For Richter and Parsons (1975) the rolls are aligned perpendicular to the motion of the lithospheric plates for young lithospheric ages but aligned parallel to plate motion for older lithosphere. In the numerical models of Korenaga and Jordan (2004), small-scale convection can occur either as Richter rolls, as sinking plumes without well-defined longitudinal rolls, as whole mantle overturn (similar to the "mantle avalanche", described by Tackley et al., 1993), or even as totally unstructured mantle flow.

The wavelength of small-scale convection, as well as its vertical extent, also remain controversial. The challenge in characterizing small-scale convection is that it is often quantified from indirect observations, such as the flattening of the seafloor subsidence curve and the decrease in heat flow for plates older than $70 \mathrm{Ma}$ (Parsons and Sclater, 1977; Cazenave et al., 1988; Stein and Stein, 1994; Doin and Fleitout, 1996; Crosby et al., 2006). Undulations in the gravity and geoid have been identified as possible signatures of small-scale convection, but with very different wavelengths, depending on the authors: $\lambda \sim 150-300 \mathrm{~km}$ for Haxby and Weissel (1986) and $\lambda \sim$ $500-1000 \mathrm{~km}$ for Cazenave et al. (1992). Through a joint study of bathymetry and geoid anomalies and a full spectral analysis, Wessel et al. (1996) show that there are several characteristic wavelengths: $160 \mathrm{~km}, 225 \mathrm{~km}, 287 \mathrm{~km}, 400 \mathrm{~km}, 660 \mathrm{~km}, 850 \mathrm{~km}, 1000 \mathrm{~km}$ and $1400 \mathrm{~km}$. For Kroenke and Wessel (2003), the wavelength representative of small-scale convection is $500 \mathrm{~km}$. For its vertical extent, although most studies agree the small-scale convection should be confined in the asthenosphere, i.e. the low viscosity layer at the base of the lithosphere (e.g., Hall and Parmentier, 2003; van Hunen et al., 2005), with a vertical extent of about $100 \mathrm{~km}$, other works include the effect of phase changes at $410-660 \mathrm{~km}$ and report instabilities reaching much larger depths for older ages (Korenaga and Jordan, 2004).

Until recently the resolution of seismic tomography models has been insufficient to provide insights into the character of small-scale convection. However, new tomography models, such as SEMUCB-WM1 (French and Romanowicz, 2014), have a high enough resolution to examine structures on scales smaller than that of whole plates. These models are being used, for example, to provide new insight into the structure and dynamics of mantle plumes (French and Romanowicz, 2015).

In this work, we use three different tomography models to assess the base of the oceanic lithosphere in the Pacific Ocean (section 2). The structure of the lithosphere is, indeed, a key factor for understanding the physics of multiscale convection and, in particular, to investigate the existence and characteristics of small-scale convection in the older part of the Pacific. Instabilities found at the lithosphere-asthenosphere boundary (LAB) are then compared to independent geophysical data (section 3) in order to constrain their origin. In section 4 we present laboratory experiments that provide complementary insights into the formation and possible structures of small-scale convection. As stated by French and Romanowicz (2014), "higher resolution global- 
scale tomographic models, producing more detailed and realistic images of seismic structure while reducing and quantifying uncertainties, provide a key avenue for constraining which phenomena seen in simulation or the lab are likely to manifest in the mantle". The results found through these approaches are then discussed and interpreted in section 5.

\section{Lithosphere destabilization constrained from tomography models}

We use tomography models to determine the base of the oceanic lithosphere for the Pacific plate. Tomography models provide a snapshot of the internal structure of the Earth, in terms of seismic velocity variations. Global tomography models have undergone major improvements in the last 30 years, especially for the characterization of large-scale features in the Earth's mantle (Panning and Romanowicz, 2006; Simmons et al., 2006, 2010; Ritsema et al., 2011; Lekíc and Romanowicz, 2011; Debayle and Ricard, 2012; French and Romanowicz, 2014, 2015). However, until recently the best lateral resolution has been of the order of $1000 \mathrm{~km}$ (Ritsema et al., 2011), leaving shorter wavelength features poorly resolved. Within this study we use three tomography models: SEMUCB-WM1 (French and Romanowicz, 2014), the 3D2018_08Sv (Debayle et al., 2016) and the tomography model designed by Isse et al. (2018). The SEMUCB-WM1 tomography model is based on the 'hybrid' waveform-inversion approach that combines the accuracy and generality of the spectral finite element method for forward modeling of the global wavefield, with non-linear asymptotic coupling theory for efficient inverse modeling. SEMUCB-WM1 describes the entire mantle structure, with a $400 \mathrm{~km}$ lateral resolution. Debayle et al. (2016) developed an S wave model of the upper mantle based on the waveform modeling of Rayleigh waves. We use the 3D2018_08Sv updated model, available on the IRIS website (https://ds.iris.edu/ds/products/emcearthmodels/). This model has a lateral resolution of $\sim 600 \mathrm{~km}$ and describes the shallowest 1000 $\mathrm{km}$ of the mantle. Isse at al. (2018) designed a surface wave tomography over the northwest part of the Pacific Ocean using waveforms and the phase speed dispersions of Love and Rayleigh waves. They provide 3D models of the Voigt average shear wave velocity as well as the radial anisotropy in the uppermost $250 \mathrm{~km}$. The lateral resolution of the shear-wave speed model, called hereafter Isse2018, is about $800 \mathrm{~km}$. French and Romanowicz (2015) use the SEMUCB-WM1 tomography model to study the morphology and characteristics of mantle plumes. In this study, we will use this model and two other models to characterize the oceanic lithosphere and, in particular, the destabilization of the lithosphere.

In the depth cross sections shown in Figure 1a-c the color scale represents the amplitude of the lateral seismic velocity anomalies, $d v s$, of the SEMUCB-WM1 tomography model, provided in percent. The $d v s$ values of the 3D2018_08Sv model are reported in Figure 1d-f, and the $d v s$ values of the Isse2018 model are reported in Figure 1g-i. The regions in yellow, such as the area near the East Pacific Rise, are associated with slower seismic velocities. The regions represented in blue are areas characterized by faster seismic velocities. These seismically fast regions generally encompass the oceanic or continental lithosphere. The lateral seismic velocity anomalies, $d v s$, have a thermal and/or compositional origin, although the thermal effect is predominant; see discussion in Adam et al (2017). If interpreted in terms of temperature variations, the yellow areas would be relatively hotter regions, such as the mid-oceanic ridges or plumes. In contrast, the blue regions correspond to relatively colder regions, such as the oceanic lithosphere.

The $d v s$ values in the oceanic lithosphere vary between 0.5 and $5 \%$ (Figures 1a-i), according to the three considered tomography models. However, as discussed above, the amplitudes of the $d v s$ 
values vary according to the considered tomography model. For example, considering a random location at longitude $180^{\circ} \mathrm{E}$, latitude $20^{\circ} \mathrm{N}$, and depth $100 \mathrm{~km}$, the $d v s$ is $4.3 \%$ according to the SEMUCB-WM1 tomography model (French and Romanowicz, 2014), 1.0\% according to the 3D2018_08Sv tomography model (Debayle et al., 2016), and 1.5\% according to the Isse2018 tomography model (Isse et al., 2018). Simiilarly, the $d v s$ is $1.1 \%$ according to the SAVANI tomography model (Auer et al., 2014) and 1.7\% according to the S40RTS tomography model (Ritsema et al., 2011) as discussed in Pandit (2020). There is then no consensus on the $d v s$ value characteristic of the oceanic lithosphere. Consequently, there is no consensus on the $d v s$ representative of the base of the lithosphere (Pandit, 2020).

Figure 1a-c clearly shows that the base of the oceanic lithosphere varies geographically and appears to be located between $d v s=1 \%$ and $d v s=2 \%$. However, as there is no clear definition on the $d v s$ corresponding to the base of the oceanic lithosphere, we have developed a method for extracting for each point, i.e. for each latitude/longitude, a $d v s$ vs. depth profile. Along this profile, we then extract the depth for which the $d v s$ is closest to a specified value. The $d v s$ values we have tested include $1 \%, 1.5 \%$ and $2 \%$. In Figure $1 \mathrm{j}$ we represent the depth to the base of the lithosphere determined with $d v s=1.5 \%$ while considering the SEMUCB-WM1 tomography model. Our method is described in more details in the Supplementary Online Material (SOM), where we also provide a study of the influence of the parameters of this method. In particular, we show that the considered isovalue $(d v s=1 \%, 1.5 \%$ or $2 \%)$ does not have a major influence on the shape of the base of the lithosphere. The chosen $d v s$ value will slightly influence the depth to the base of the lithosphere, but not the location of patterns at its base, which is the topic of this study. Note that the surface defined by $d v s=1.5 \%$ with SEMUCB-WM1 tomography model corresponds roughly to the $1650 \mathrm{~K}$ isotherm if one considers the 1D temperature reference model published by Stein and Stein (1992), and to the $1500 \mathrm{~K}$ isotherm if one considers the 1D temperature reference model published by Parsons and Sclater (1977) (see SOM for more details). These isotherms are in agreement with the range provided by the most-widely used plate models (Parsons and Sclater, 1977; Stein and Stein, 1992).

In Figure $1 \mathrm{k}$ and 11, we show the depth to the base of the lithosphere determined with 3D2018_08Sv and Isse2018 models, respectively. As the $d v s$ varies with the tomography models, we cannot use the same $d v s$ as used with SEMUCB-WM1 $(d v s=1.5 \%)$ to assess the base of the lithosphere for all tomography models. In Figure 1d-f, we can see that the positive $d v s$ values of the 3D2018_08Sv model are confined to shallower depths than produced by the SEMUCB-WM1 model (Figure 1a-c). If we use a $d v s=1.5 \%$ to define the LAB from the 3D2018_08Sv model, the depth of this LAB would vary between 50 and $130 \mathrm{~km}$, instead of 50-180 km depths observed for SEMUCB-WM1. In order to obtain a LAB that varies between the same depth ranges for all the considered tomography models, the LAB computed for the 3D2018_08Sv model corresponds to $d v s=0.5 \%$, and the LAB computed for the Isse 2018 corresponds to $d v s=2.0 \%$. Note that the pattern of the LAB variations displayed in Figure $1 \mathrm{j}-1$ does not noticeably change while varying the $d v s$ defining it (see SOM).

The profiles along which we investigate the structure of the lithosphere in Figure 1 a-i are reported on the LAB maps displayed in panels $\mathrm{j}-1$. Profiles AA' and BB' are representative of the presentday direction of the Pacific plate motion, and have been computed by using the Nuvel1A model, in the HS3 reference frame (Gripp and Gordon, 2002). The CC' profile is perpendicular to AA' 
and BB'. The depth to the base of the lithosphere varies between 50 and $180 \mathrm{~km}$, which is shown graphically in the maps in Figure 1j-1. Greater depths are observed in the northwest of the Pacific plate, far from the mid-oceanic ridges. This is predictable, as the lithosphere of the northwest Pacific plate is older and should, in theory, be thicker. The gray areas represent regions for which the base of the lithosphere could not be determined (see SOM for further explanations). In the proximity of mid-oceanic ridges, the base of the lithosphere cannot be determined as the lithosphere is not actually "seen" in the tomography model. In these regions, we see broad seismically slow regions, represented in yellow, corresponding to mantle upwelling at the spreading centers (see depth cross sections AA' and BB' in Figure 1a,b). For the SEMUCB-WM1 tomography model, the LAB could not be determined several thousand of kilometers away from the mid-oceanic ridge (Figure 1j), while for the 3D2018_08Sv model, the LAB determination was only problematic in regions close to mid-oceanic ridges (Figure 1k). Isse 2018 is only provided over the northwest Pacific, so the LAB determination has not been problematic.

Further away from mid-oceanic ridges, several anomalous regions are observed (Figure $1 \mathrm{j}-\mathrm{o}$ ). The LAB patterns differ according to the considered tomography models, but also display some similarities. For the SEMUCB-WM1 tomography model, the most noticeable anomalies, associated with the highest amplitudes, are the anomalies represented in blue, corresponding to regions where the base of the lithosphere is deeper than in the surrounding areas (i.e. $\sim 120-180$ $\mathrm{km}$ deep), (Figure 1j,m). These lithospheric anomalies seem to be distributed along the direction of the present-day Pacific plate motion, shown by the AA' and BB' profiles (Figure 1j,m). Similar observations can be made for the 3D2018_08Sv model (Figure 1k,n), even if the location, amplitude and pattern of the LAB determined from the this model differs from the ones determined from the SEMUCB-WM1 model. The anomalous regions, associated with thicker lithosphere according to the 3D2018_08Sv model, seem to be distributed along the direction of the presentday Pacific plate motion (Figure 1k,n). This pattern is, however, not recovered from the Isse 2018 model (Figure 1 1,o). In the LAB derived from this model, we can see, however, that there are several anomalies perpendicular to the direction of the Pacific plate motion, i.e. perpendicular to the AA' and BB' profiles. This appears more clearly in the zoom in displayed in panel o, where we also report the $100 \mathrm{~km}$ isocontour of the LAB.

In the direction perpendicular to the present-day Pacific plate motion, i.e. along the CC' profile, the lithospheric anomalies determined from the SEMUCB-WM1 and 3D2018_08Sv models seem to be confined in specific regions. By looking along the directions parallel and perpendicular to the plate motion, we can see that the lithospheric anomalies are localized in corridors elongated along the present-day direction of Pacific plate motion. The LAB computed from the 3D2018_08Sv and Isse2018 tomography models show anomalies that seems "smeared" along the direction perpendicular to the of the present-day motion of the Pacific plate, i.e. along the CC' profile.

Tomography models differ from each other mainly because of the different data considered as an input, and on the inversion method (see discussion in Debayle et al., 2016). Tomography models also have different resolutions. SEMUCB-WM1 and 3D2018_08Sv models are designed by using waveform inversion, the most promising approach for surface waves (Debayle et al., 2018) while Isse et al. (2018) use other inversion methods. This could explain some of the discrepancies noticed here between Isse2018 and the two other tomography models. Moreover, Isse et al. (2018) 
integrated an age-dependency in their model, i.e. they created a reference age-dependent shearwave speed model that they used as a starting condition for tomography iteration. However, as we will discuss in section 3.1, the correlation between the LAB and the seafloor age is not straightforward.

As explained above, the lateral resolution differs according to the considered tomography models, with the resolution of the SEMUCB-WM1 model being approximately half that of the Isse 2018 model, i.e. $\sim 400 \mathrm{~km}$ vs $800 \mathrm{~km}$, and 3D2018_08Sv intermediate. Therefore, Isse2018 is less resolved than SEMUCB-WM1 and 3D2018_08Sv. This can be observed in the depth-cross sections shown in Figures 1a-i.

Isse et al. (2018) also provide the radial anisotropy, which was obtained without an a priori agedependency, unlike their shear-wave speed model. In Figure1p we report the depth corresponding to the maximal anisotropy. The anisotropy is maximal along regions associated with downwellings or upwellings along the radial direction. We observe several anomalous regions, where the maximal anisotropy is deeper than in the surrounding regions, and reaches depths around $180 \mathrm{~km}$. These anomalous regions are distributed along the direction of the present-day Pacific plate motion. This indicates a connection between mantle downwellings /upwellings occurring at a scale of 2,000 km and the general direction of the Pacific plate motion. In the following section, we investigate their correlation with independent geophysical data in order to better constrain the phenomena at the origin of the abnormally thick lithosphere.

3. Correlation between lithospheric instabilities and geophysical data

\subsection{Seafloor age and plate kinematics}

In theory, if the lithospheric thickness is a function of age (i.e. amount of time available for cooling since formation at a mid-ocean ridge), then the depth to the base of the lithosphere should correlate with age. Deviations from that simple correlation must reflect other processes. In Figure 2 we investigate the correlation between locations of lithosphere instabilities, i.e. regions of anomalously thick lithosphere, and seafloor age. For the SEMUCB-WM1 model (Figure 2a), we report the seafloor age only for regions where the base of the lithosphere was successfully determined. This excludes regions near mid-oceanic ridges and hot mantle plumes, where the lithosphere cannot be "seen" in this tomography model. The LAB determination was less problematic for 3D2018_08Sv (Figure 2b) and Isse2018 (Figure 2c). Isse2018 only covers the northwestern part of the Pacific plate though.

The youngest seafloor age for which the base of the lithosphere can be determined is $\sim 50 \mathrm{Ma}$ for SEMUCB-WM1, and $\sim 70 \mathrm{Ma}$ for Isse2018. The LAB determined from the 3D2018_08Sv encompasses seafloor of almost all ages (Figure $2 \mathrm{~b}$ ). For relatively young seafloor (0-90 Ma) the lithosphere has a normal thickness of 50-100 km. The definition of "abnormally thick" lithosphere differs according to the authors. For Stein and Stein (1992), the asymptotical lithosphere thickness is $95 \pm 15 \mathrm{~km}$, while for Parsons and Sclater (1977) it is $125+10 \mathrm{~km}$. In textbooks, the asymptotical thickness is about $100 \mathrm{~km}$ (Turcotte and Schubert, 1982; Schubert et al., 2001). In Figure 2a the red contours encompass regions where the lithosphere determined from the SEMUCB-WM1 model is thicker than $120 \mathrm{~km}$, while inside the white contours, the lithosphere in thicker than 150 
$\mathrm{km}$. Therefore, these contours delimit regions characterized by abnormally thick lithosphere, according to all the previously discussed definitions. The 120 and $150 \mathrm{~km}$ isocontours of the base of the lithosphere determined with the Isse 2018 model are reported in Figure $2 \mathrm{c}$ as well. For the 3D2018_08Sv model, however, as positive $d v s$ values are confined to shallower depths relative to other models, there are no $150 \mathrm{~km}$ contours available, and $140 \mathrm{~km}$ iscontours are sparse. For this model, the red contours encompass regions where the lithosphere is thicker than $120 \mathrm{~km}$, while inside the white contours, the lithosphere is thicker than $130 \mathrm{~km}$.

The anomalous regions delimited by these iscontours are in areas where the seafloor is older than 100-120 Ma: older than $100 \mathrm{Ma}$ according to the SEMUCB-WM1, older than $~ 110 \mathrm{Ma}$ according to the Isse2018 model, and older than $\sim 120 \mathrm{Ma}$ according to the 3D2018_08Sv model. Although thicker lithosphere is generally older than 100-120 Ma, the anomalies do not correlate with the isochrones. Moreover, the thickest lithosphere is not associated with the oldest seafloor ages. In Figure 2 we also report the kinematic velocities representative of the present-day direction of the Pacific plate motion (white arrows), computed from the Nuvel1A model, in the HS3 reference frame (Gripp and Gordon, 2002). The lithosphere anomalies are clearly elongated along the present-day direction of the Pacific plate motion, if one considers the anomalies derived from the SEMUCB-WM1 and the 3D2018_08Sv models (Figure 2a,b). This qualitative correlation suggests a link between the regions of anomalously thick lithosphere and present-day mantle dynamics, rather than with absolute seafloor age.

\subsection{Volcanic features}

Variations in lithosphere thickness can possibly originate from hot mantle plumes, which could modify the thermal structure and, therefore, the mechanical structure of the lithosphere. Therefore, in this section we investigate the correlation between the regions characterized by thicker lithosphere and volcanic features. The names of the main topographic features on the Pacific plate are reported on the bathymetry map (Figure 3a). The red stars represent active hotspots and are extracted from King and Adam (2014). Their location does not seem to correlate with the regions of thicker lithospheric identified by our study (white and red contours in Figure 3c-d). Hotspot chains are created by the interaction of a hot rising mantle plume and a drifting lithosphere. Therefore, the mantle around these regions appears as seismically slow, due to the higher temperature associated with plumes, and/or to the melting these plumes induce, as discussed in more details in French and Romanowicz (2015) and Styles et al. (2011). The yellow regions in the depth cross sections displayed in Figure $3 \mathrm{e}-\mathrm{j}$ are mantle plumes, characterized by negative $d v s$. Their names are indicated in each panel. The white line in Figure $3 \mathrm{e}-\mathrm{j}$ represents our estimate of the base of the lithosphere for each of the considered tomography models. The lack of white lines around plumes such as Hawaii, Samoa or Rarotonga in Figure 3e, h indicates that our method does not select the LAB in proximity to plumes when using the SEMUCB-WM1 model. Indeed, the method excludes regions for which the shallowest mantle displays negative $d v s$. For the other tomography models the LAB is determined even around plumes (Figure 3f,i-h). The lithosphere seems thinned around Samoa, according to the 3D2018_08Sv model (Figure 3f), and around Hawaii, according to the Isse2018 model (Figure 3j). Along the same depth cross sections, we can also see that the lithosphere is not significantly thicker in regions surrounding these plumes. 
The northwestern part of the Pacific plate is very old (older than $100 \mathrm{Ma}$ ) and, therefore, covered by numerous volcanic features, including oceanic plateaus and old volcanic chains (Figure 3b-d). The volcanism ages discussed in this paragraph have been extracted from the review papers by Clouard and Bonneville (2004) and Ito and van Keken (2007), which also contain detailed descriptions of the volcanic features. Some of these volcanic features, such as the Mid-Pacific Mountains, the Japanese seamounts and the Magellan seamounts are emplaced in regions associated with abnormally thick lithosphere according to the SEMUCB-WM1 model, i.e. as shown by the red and white contours reported in Figure 3b. The thicker lithosphere regions defined from the 3D2018_08Sv model encompass Shatsky Rise (SR) and the Marshall and Magellan seamounts but not the Mid-Pacific Mountains (Figure 3c). According to the Isse2018 model, the Shatsky Rise, the Markus-Wake and the Magellan seamounts are emplaced on thicker lithosphere (Figure $3 \mathrm{~d}$ ). The Mid-Pacific Mountains are an old oceanic plateau, with volcanism ages ranging between 73.5 and 110.7 Ma. The Japanese and the Magellan seamounts are volcanic chains with ages of 71.6-108.3 Ma and 87-129 Ma, respectively.

Most of the other volcanic features are, however, emplaced over a lithosphere of normal thickness $(\sim 100-120 \mathrm{~km})$. This is the case for the Emperor chain, the Marshall seamounts, most of the volcanoes composing the Markus-Wake seamounts, and the Shatsky and Hess ridges based on the SEMUCB-WM1 model (Figure 3b). Moreover, some regions characterized by thicker lithosphere are not associated with any volcanic features, such as the region encompassed in the white contour centred at longitude $170^{\circ} \mathrm{E}$ and latitude $25^{\circ} \mathrm{N}$ (Figure $3 \mathrm{~b}$ ). The region included in the large white contour centred at longitude $150^{\circ} \mathrm{E}$ and latitude $35^{\circ} \mathrm{N}$ does not contain any volcanic feature besides the Japanese seamounts (Figure 3b). Similar observation can be done for Figures $3 \mathrm{c}$ and $\mathrm{d}$. Considering that the seafloor in the northwest Pacific is 100-180 Ma old, it is statistically unlikely that it has not been loaded by a volcanic feature at some point since its creation. We conclude that there is no significant correlation between lithosphere thickness and the emplacement of old or young volcanic features, whatever the considered tomography model. The lack of correlation between regions associated with abnormally thick lithosphere and volcanism indicates that distinct phenomena are at their origin.

\subsection{Long wavelength bathymetric anomalies and dynamic topography}

In Figure 4a we can see that the bathymetry displays minima along the northwestern part of the Pacific plate, where we pointed out regions associated with abnormally thick lithosphere. This is more apparent when we look at the filtered bathymetry (Figure 4b). The bathymetry has been filtered to remove the short-wavelength features, in order to allow a better visual comparison between the bathymetry and the dynamic topography. We used the MiFil method (Adam et al., 2005), which requires two stages: minimization and filtering though a median filter. We used radius of 200 and $500 \mathrm{~km}$ for the minimizing and median filters respectively. To investigate quantitatively how an abnormally thick lithosphere can influence the bathymetry, we compute the dynamic topography, i.e. the stress field generated at the surface by the instantaneous mantle flow.

To obtain the dynamic topography, we convert the seismic velocity anomalies provided by the tomography models [SEMUCB-WM1, (French and Romanowicz., 2014) and 3D2018_08Sv (Debayle et al., 2016)] into density anomalies using the conversion law provided by Karato (2008) and model the instantaneous flow induced by those density anomalies. SEMUCB-WM1 describes 
the whole mantle and, therefore, we model the convection at the whole mantle scale. 3D2018_08Sv describes only the shallowest $1000 \mathrm{~km}$ of the mantle. For this model we have modeled the convection pattern in the upper mantle only, i.e. for depths $0-660 \mathrm{~km}$. We have not modeled the convection pattern and the induced dynamic topography using Isse2018, as this model only describes the shallowest $250 \mathrm{~km}$ of the mantle. We also consider a plate model in which the lithosphere structure is approximated by the model proposed by Parsons and Sclater (1977): the lithosphere thickens as the square root of the seafloor age for young seafloor. For seafloor older than $70 \mathrm{Ma}$, the lithosphere has an asymptotic thickness of $125 \mathrm{~km}$. We impose a density anomaly of $40 \mathrm{~kg} \mathrm{~m}^{-3}$ in the lithosphere while the density in the mantle is null. Similarly, we also consider a half-space model, where the thickness of the lithosphere scales as the square root of the seafloor age all along the Pacific plate, without any flattening. The maximal thickness, $125 \mathrm{~km}$, is reached at the oldest age of the seafloor $(\sim 175 \mathrm{Ma})$.

To solve for instantaneous mantle flow driven by density anomalies in a global 3D spherical shell geometry using spherical polar coordinates $(r, \theta, \varphi)$, we solve the conservation equations of mass and momentum. In formulating the basic equations that govern the instantaneous mantle flow, the length $L$, velocity $\boldsymbol{v}$, stress (or pressure) $\boldsymbol{\sigma}$, are non-dimensionalized as follows:

$$
L=r_{1} L^{\prime}, \quad \boldsymbol{v}=\frac{\kappa_{0}}{r_{1}} \boldsymbol{v}^{\prime}, \boldsymbol{\sigma}=\frac{\eta_{0} \kappa_{0}}{r_{1}^{2}} \boldsymbol{\sigma}^{\prime} \text { (1) }
$$

where $r_{1}$ denotes the radius of the Earth, $\kappa_{0}$, the reference thermal diffusivity, and $\eta_{0}$, the reference viscosity (Table S1). In these equations, symbols with primes represent non-dimensional quantities. However, for simplicity, the primes are omitted hereinafter.

Using these dimensionless factors, the dimensionless conservation equations for mass and momentum governing the instantaneous mantle flow under the Boussinesq approximation are expressed respectively as:

$$
\begin{gathered}
\boldsymbol{\nabla} \cdot \boldsymbol{v}=0(2) \\
-\nabla p+\nabla \cdot\left[\eta\left(\nabla \boldsymbol{v}+\boldsymbol{\nabla} \boldsymbol{v}^{t r}\right)\right]+R a_{i} \delta \rho \boldsymbol{e}_{\boldsymbol{r}}=0 \text { (3) }
\end{gathered}
$$

where $v$ is the velocity vector, $p$ the dynamic pressure, $\eta$ the viscosity, $\delta \rho$ the density anomaly, $R a_{i}$ the instantaneous Rayleigh number and $\boldsymbol{e}_{r}$, the unit vector in the radial direction. The superscript tr indicates the tensor transpose. The instantaneous Rayleigh number $R a_{i}$ (Yoshida, 2008) used in our computation is given by

$$
R a_{i}=\frac{\rho_{0} g b^{3}}{\kappa_{0} \eta_{0}}(4)
$$

where $\rho_{0}$ is the reference density, $g$ the gravitational acceleration, $\kappa_{0}$ the reference thermal diffusivity, $\eta_{0}$ the reference viscosity, and $b$ the mantle thickness considered in the model. The physical values used in this study are listed in Table S1.

The calculation of the instantaneous mantle flow in a global 3D spherical-shell geometry has been performed using the finite-volume (FV) based mantle convection code, ConvRS (Yoshida, 2008; 2010; Adam et al., 2010; 2014). The number of FVs used is 132 (in $r$ ) $\times 45$ (in $\theta) \times 90$ (in $\varphi$ ), for the whole mantle calculations, and 32 (in $r$ ) $\times 45$ (in $\theta$ ) $\times 90$ (in $\varphi$ ), for the upper mantle calculations. This means that the numerical resolution is four degrees along the horizontal directions and $22 \mathrm{~km}$ along the radial direction. The boundary conditions at the top and bottom of mantle are impermeable and shear-stress free.

Once we obtained the velocity and the stress field of the instantaneous mantle flow, the dynamic 
topography and geoid anomaly can be calculated. The resulting normal stress acting on the top surface boundary $\left(\sigma_{r r}\right)$ is

$$
\sigma_{r r}=-p+2 \eta \frac{\partial v_{r}}{\partial r}(5)
$$

where $v_{r}$ is the radial velocity. The dynamic topography $\delta h$ is obtained from the normal stress through the equation

$$
\delta h=\frac{\sigma_{r r}-\left\langle\sigma_{r r}\right\rangle}{\Delta \rho_{s} g}(6)
$$

where $\left\langle\sigma_{r r}\right\rangle$ is the averaged $\sigma_{r r}$ over the top surface boundary, $\Delta \rho_{s}$ is the density contrast between the mantle and sea water and $g$, the gravity acceleration. We use a depth and temperature dependent viscosity, discussed in more details in section 5.

The dynamic topography obtained for each of the designed mantle and lithosphere structures is displayed in Figure 4c-f. The dynamic topography obtained from the SEMUCB-WM1 (Figure 4c) and 3D2018_08Sv (Figure 4d) models partially reproduces the minima observed in the bathymetry (Figure 4a,b). As expected, the dynamic topography computed from the plate model is almost flat in the northwest Pacific, as the seafloor is older than $70 \mathrm{Ma}$. The dynamic topography computed for the half space model displays a minimum over the oldest seafloor, encompassed in the white $150 \mathrm{Ma}$ isochrone (Figure 4f), which does not, therefore, account for the minima observed in the bathymetry (Figure 4a,b). Variations of the seafloor depth along the AA' profile (located in Figure 4a) and correlation with the dynamic topographies are shown in panels g-i. Although almost all the computed dynamic topographies reproduce the subsidence trend fairly well, the minima observed in the bathymetry (Figure 4a,b) are only reproduced from the SEMUCB-WM1 and 3D2018_08Sv models, for which we observe anomalies at the base of the lithosphere aligned along the direction of the present-day Pacific plate motion.

The point of this section is to show that the lithospheric anomalies and the effects they induce are observed in other independent observables, such as the bathymetry. The long wavelength variations of the bathymetry along the AA' profile are well recovered by the dynamic topography computed from the SEMUCB-WM1 model (Figure 4j). These variations are created by the flow occurring in the underlying mantle. Although the flow has a complex pattern, created by the lithospheric anomalies, and other anomalies located deeper in the mantle, we can see that in the regions associated with thicker lithosphere there is mainly a downwelling flow (blue, red, and yellow dashed boxes in Figure 4k). This downwelling flow is partially created by the abnormally thick lithosphere and is at the origin of the negative dynamic topography (Figure 4c).

\subsection{Geoid}

The geoid is another independent observable that brings important constraints on the mantle structure and dynamics. The geoid is an equipotential surface of the gravitational field which, to a first order, can be approximated by the mean ocean's surface. One of the main difficulties in using the geoid to constrain a phenomenon is determining which long wavelength gravitational field best represents the studied phenomenon. DeLaughter et al. (1999) applied a spatial bandpass filtering 
to geoid data to extract the age-dependent lithospheric cooling signal and found that the lithospheric cooling signals are largest at the wavelengths corresponding to the degrees 14 to 39 . The morphology of the lithospheric anomalies determined from the SEMUCB-WM1 tomography models provides supplementary constraints. The lithospheric anomalies we identified are roughly $4,000 \mathrm{~km}$ long and 1,000 km wide. Considering that the circumference of the Earth is $40,075 \mathrm{~km}$, these wavelengths correspond to $\sim$ degrees $10(\sim 40,075 / 4,000)$ and $40(\sim 40,075 / 1,000)$, respectively. In Figures 5 a, b we display the geoid anomalies for orders 10-39 (l=10-39) and 1440 (l=14-40). The EGM2008 geoid (Pavlis et al., 2012) has been used in this study. The regions characterized by a thicker lithosphere are associated with negative geoid anomalies with amplitude of $\sim-4 \mathrm{~m}$ for both these order ranges.

A density anomaly (mass excess or deficit) located in the mantle or the lithosphere affects the gravity field in two main ways. First, it affects the gravity field directly. Mantle convective flow induced by density anomalies distorts surfaces such as the core-mantle boundary (CMB), or any other interface defined by phase or compositional changes. At the surface, this distortion is known as the dynamic topography, discussed in the previous subsection. In other words, the geoid anomaly at the surface can be computed through equation 7 .

$$
\delta N^{n m}=\sum_{n=n_{\min }}^{n_{\max }} \sum_{m=0}^{n}\left\{\frac{4 \pi G}{g(2 n+1)}\left[\int_{r_{c}}^{r_{s}} \delta \rho^{n m}(r) r\left(\frac{r}{r_{s}}\right)^{n+1} d r+\Delta \rho_{s} \delta h_{s}^{n m} r_{s}+\Delta \rho_{s} \delta h_{c}^{n m} r_{c}\left(\frac{r_{c}}{r_{s}}\right)^{n+1}\right]\right\}
$$

where $G$ is the gravitational constant, $r_{s}$ is the Earth's radius, $r_{c}$ is the core radius, $n$ and $m$ are the spherical harmonic degree and order, and $n_{\min }$ and $n_{\max }$ are the minimum and maximum degrees. The geoid anomaly is computed through the spherical harmonic expansions, by integrating the density anomalies from the core to the surface $\left(r_{c} \leq r \leq r_{s}\right)$ (first term), and considering the geoid anomalies produced by the dynamic topographies at the top surface and at the CMB (second and third terms).

Geoid anomalies are the sum of several phenomena occurring at different wavelengths and depths. If we only consider the contribution of the thicker lithosphere, the observed geoid anomaly can be interpreted as follows. Regions of abnormally thick lithosphere should, in theory, be associated with a positive internal geoid anomaly (first term in equation 7), as the thicker lithosphere is an extra mass. As discussed in the previous section, the thicker lithosphere creates a downwelling flow, which induce a negative dynamic topography at the surface, and therefore a negative geoid anomaly (second term in equation 7). The effect of the CMB dynamic topography is generally negligible when compared to the first terms. The total geoid anomaly will depend on the trade-off between the positive buoyancy created by the lithospheric drips, denser than the surrounding mantle, and the negative geoid anomaly created by dynamic topography induced by the downwelling flow. As the geoid anomaly observed over the regions characterized by thicker lithosphere is negative, the effect of the dynamic topography seems to prevail over the extra mass effect.

Through the geodynamic model based on the SEMUCB-WM1 tomography model (described in the previous section), we model the geoid anomalies for orders $1=10-40$ and $l=14-39$ (Figure $5 \mathrm{c}$ 
and d). As we need the whole mantle structure and dynamics to model the geoid, we cannot estimate the geoid anomalies from the 3D2018_08Sv and Isse2018 models. The modelled geoid anomalies are mostly negative over regions associated with a thicker lithosphere and display a fair correlation with the locations of thicker lithosphere.

\subsection{Interpretation of the lithospheric anomalies}

We use three tomography models [SEMUCB-WM1 (French and Romanowicz, 2014), 3D2018_08Sv (Debayle et al., 2016) and Isse2018 (Isse et al.,2018)] to determine regions associated with thicker lithosphere in the Pacific Ocean (Figure 1j-o). Variations in the lithosphere thickness are generally associated, to a first order, with variations of the seafloor age (Parsons and Sclater, 1977; Stein and Stein, 1992) or with interaction between a mantle plume and the overriding lithosphere (Crough, 1983; Sleep, 1990; Adam et al., 2010). We show, however, that there is no significant correlation between abnormally thick lithosphere and volcanism. Moreover, even if overthickened lithosphere is found on seafloors older than 100-120 Ma, there is no correlation between the shape of the lithospheric anomalies and the isochrons. The lithosphere anomalies computed from the SEMUCB-WM1 and 3D2018_08Sv models are elongated along the presentday direction of the Pacific plate motion. This suggests that these lithospheric anomalies are created by present-day mantle dynamics. These anomalous regions, where the base of the lithosphere is deeper than the surrounding areas, are also observed in other independent data such as bathymetry and geoid. We interpret these anomalous regions as lithospheric instabilities or cold drips. The most likely origin for these lithospheric drips is secondary or small-scale convection induced by the coupling between the lithosphere and the underlying mantle flow. In order to understand the morphology and dynamics of the lithospheric instabilities, we present in the next section an experimental study investigating the formation and structure of small-scale convection.

\section{Experimental modelling}

The goal of this experimental study is to investigate the interaction between a convective largescale flow, analogous to large-scale mantle convection, and small-scale instabilities developing under an upper cold boundary layer, analogous to instabilities developing at the base of the lithosphere. The resulting small-scale convective patterns will be described and compared to the observations from the tomography model (section 2).

\subsection{Experimental setup}

\subsubsection{Description}

The experiments are performed in a tank of inner dimensions $L=40 \mathrm{~cm}$ length, $l=30 \mathrm{~cm}$ width and $h=20 \mathrm{~cm}$ height (Figure 6). One side of the tank and its upper and lower walls are copper plates kept at constant temperature. The other walls are made of plexiglass. The system is covered

with Styrofoam ${ }^{\mathrm{TM}} 4 \mathrm{~cm}$-thick, to minimize heat loss. A large-scale flow is forced by a lateral heating at temperature $T_{\text {lat }}$ (Curlet, 1976; Nataf et al., 1981, Crambes, 2000, Vidal et al., 2003), 
while the upper and lower walls are cooled at constant temperature $T_{u p} \approx T_{\text {low }}$. The coordinates $(x, y, z)$ are indicated in Figure 6, where the reference $x=y=z=0$ is taken at the bottom-right corner of the tank. Hereafter, we will refer to the $x$-direction as the longitudinal direction (parallel to the large-scale shear flow) and to the $y$-direction as the transverse direction (perpendicular to the large-scale shear flow). Note that we do not heat the bottom boundary, since this would generate hot rising plumes, interfering with the cold dripping instabilities.

Different fluids have been used in the experiments. Constant-viscosity fluids were made by mixing water and hydroxyethylcellulose $\left(\mathrm{Natrosol}^{\mathrm{TM}}\right)$. The viscosity of these solutions is an increasing function of the Natrosol ${ }^{\mathrm{TM}}$ concentration in water (Tait and Jaupart, 1989; Davaille, 1999), and remains constant within $20 \%$ when temperature varies. $\mathrm{Natrosol}^{\mathrm{TM}}$ makes it possible to increase the viscosity, and therefore the Prandtl number $\operatorname{Pr}$ of the solution, so that the system is always in the viscosity dominated regime, i.e. $P r \geq 100$ (Krishnamurti, 1970). In order to study the effect of a temperature-dependent viscosity, three different syrups have been used: two glucose syrups (SYRAL), aqueous saccharide solution purified and concentrated GS6080 and GS6075, hereafter designated as SG1 and SG2; and a highly purified sugar syrup, SI9566 (SYRAL), obtained by inverting at $95 \%$ and concentrating a saccharose solution, hereafter named SI. The fluid densities has been measured with an oscillating U-tube Anton Paar DMA 5000 density meter, and their viscosities with a rotating HAAKE RV20 viscosimeter. The fluids' physical properties are presented in Table 1.

\subsubsection{Measurements}

To analyze the convective pattern in the tank, we have performed (1) direct visualization of the temperature field; (2) local temperature measurements and (3) Particle Image Velocimetry (PIV) measurements. The light source is a compact solid-state diode-pumped, frequency doubled $\mathrm{Nd}$ :Vanadate (Nd:YVO4) laser, providing single-frequency green output $(532 \mathrm{~nm})$ at high power level (up to 2W) (Davaille et al., 2008; Limare et al., 2008). The laser beam is opened to a light sheet by a cylindrical divergent lens (Figure 6). Images are recorded at $90^{\circ}$ from the laser sheet with a digital camera (Canon 8.2 Mpixels) or with a black and white charge-coupled device (CCD LaVision 1280x1020 pixels). Direct images of the temperature field are provided by thermochromic liquid crystals (Hallcrest), which have the property to brighten in a given, narrow temperature range $\left(0.1^{\circ} \mathrm{C}\right.$ precision). Four liquid crystal slurries $(10 \mathrm{C} 2 \mathrm{~W}, 24 \mathrm{C} 2 \mathrm{~W}, 31 \mathrm{C} 2 \mathrm{~W}$ and $40 \mathrm{C} 2 \mathrm{~W}$ ) are introduced and mixed homogeneously in all the fluids used for the experiments. As they are miscible in all proportions and the mass introduced is negligible with respect to the total mass of fluid in the tank, they do not change the fluid properties. The bright lines appearing in the images therefore correspond to isotherms $10^{\circ} \mathrm{C}, 24.5^{\circ} \mathrm{C}, 31.3^{\circ} \mathrm{C}$ and $40.3^{\circ} \mathrm{C}$ (Figure $7 \mathrm{a}$, for sake of clarity, the image colors have been inverted and the bright lines appear in black). Local vertical temperature profiles are measured by four different thermocouple probes (diameter $2 \mathrm{~mm}$ ). Between 7 and 16 thermocouples are fixed on each probe, which can be located at different distances from the vertical hot wall. Additional thermocouples are used to record the top, bottom and lateral wall temperature. The time step between two temperature acquisitions for all thermocouples is imposed by the monitoring system at $\Delta t=30 \mathrm{~s}$. Finally, the velocity field is obtained by seeding the fluid with micrometric borosilicate glass particles (Sphericel® 110P8, 9$13 \mathrm{~mm}$ ) of density $1100 \pm 50 \mathrm{~kg} \cdot \mathrm{m}^{-3}$, suitable for liquid flow applications. Particule Image 
Velocimetry (PIV) analysis is performed using the DaVis PIV Package (LaVision, Germany, 2003), based on cross-correlation computation.

\subsubsection{Experiments and dimensionless parameters}

A total of 18 experiments have been performed (see Table 2). In the system where convection is driven by the lateral hot wall, a key dimensionless parameter is the Rayleigh number defined with the temperature difference between the lateral and upper wall:

$R a=\frac{\alpha g\left(T_{l a t}-T_{u p}\right) h^{3}}{\kappa v}$

where $\alpha$ is the coefficient of thermal expansion, $g$ the gravitational acceleration and $k$ the thermal diffusivity. $R a$ expresses the balance between the driving buoyancy forces and the two diffusive processes (heat and momentum) that retard the motion and tend to stabilize it. The second dimensionless parameter, quantifying the balance between thermal and mechanical diffusion, is the Prandtl number

$\operatorname{Pr}=\frac{v}{\kappa}$

where $v=\eta / \rho$ is the fluid kinematic viscosity, with $\eta$ the dynamic viscosity and $\rho$ the fluid density. Table 2 gives $R a_{\text {lat }}$ and $\operatorname{Pr}$ for each experiment. When the fluid properties vary with temperature, the parameters are estimated at $\left(T_{\text {lat }}+T_{u p}\right) / 2$. The Rayleigh number in our experiments ranges between $1.2 \times 10^{5}$ and $5.3 \times 10^{7}$ and the Prandtl number between 700 and $1.96 \times 10^{5}$. The latter values ensure that there is no inertia in the system, in good similarity with the Earth's mantle.

Each experiment is conducted as follows. Initially, the cold bath sluice is opened so that both the upper and lower plates are maintained at a constant cold temperature. After waiting for the bulk to be at the same uniform temperature, the hot bath sluice is opened. We then wait for a time $t>$ $\tau_{\text {diff }}$, where $\tau_{\text {diff }}$ is the characteristic diffusive time for each experiment (see Table 1), which can be up to four days. All measurements are performed in this regime, when the large-scale convection pattern is fully formed and stationary. In our experimental conditions, fluid motions are slow, and each experiment ran, from start to end, between a couple of days and a month, depending on the nature of the fluid. In order to record the temperature fluctuations in the system, data acquisitions are made over a time period ranging from half an hour, for the less viscous fluids, to up to three days for the most viscous glucose syrup (GS1).

\subsection{Interaction between two scales of convection}

In all experiments, two scales of convective motion have been observed: 1) a large-scale roll, with axis parallel to the hot wall, encircling the whole tank; and 2) small-scale instabilities that develop under the upper cold thermal boundary layer.

\subsubsection{Large-scale convection}


The vertical heated plate imposes a horizontal temperature gradient on the fluid. In this particular geometry, the system is always unstable, and no critical Rayleigh number has to be exceeded to generate convection in the fluid.. Figure 7a shows an example of the temperature field in the cell on a vertical cross-section normal to the lateral hot wall. The fluid rises along the vertical heated wall, then flows under the horizontal upper cold plate, and finally sinks down to form the return flow. The large convective cell occupies the whole tank length in the $x$-direction.

Figure $7 \mathrm{~b}$ shows an example of the vertical variation of the temperature $T$ and the horizontal component $u$ of fluid velocity. The temperature maximum is associated with a horizontal hot intrusion ('jet') that flows under the upper cold boundary. This feature has already been documented in experiments at high Rayleigh number performed in rectangular cavities with differentially heated end walls (Bejan et al., 1981). The jet is associated with a low viscosity zone, for fluids with a temperature-dependent viscosity. The core of the cell is stratified in temperature and velocity (Figure 7b), except for the less viscous sugar syrup SI1, for which the hot jet intrusion is confined close to the solid boundary, and the core is stagnant and of constant temperature $T_{m}$. For all other experiments, the core temperature displays a vertical stable stratification. The temperature in the inner region varies linearly with depth (Figure 7b), whereas it is independent of the longitudinal position along the $x$-axis. It is thus possible to define for all experiments the core temperature $T_{m}$ as the temperature where the horizontal velocity component changes sign. We note $\delta_{\text {shear }}$, the shear zone thickness, that is defined as the region between the upper plate and the stratified core (Figure 7b).

As the hot jet flows under the upper thermal boundary layer, the vertical temperature gradient is potentially unstable between the cold upper boundary and the hot large-scale current. This mechanism is responsible for the formation of small-scale instabilities (see below) that descend from the upper cold boundary layer some distance away from the lateral wall and are sheared away by the large-scale flow.

\subsubsection{Small-scale convection: 2D stationary vs. 3D time-dependent structures}

For all experiments, small-scale instabilities have been observed in the shear zone under the upper cold thermal boundary layer. They always appear at a fixed distance from the hot wall and consist of small cold 'drips'. This is consistent with the hypothesis of boundary layer instabilities: the upper cold boundary layer grows away from the hot wall, reaches a critical thickness and develops instabilities. If the instabilities were created by amplitude modulation and spatial oscillations of the large-scale convection cell, due to its adjustment to system dimensions, they would be observed everywhere in the tank (Segel, 1969; Busse and Whitehead, 1974). This is not the case in our experiments, which rules out the amplitude modulation hypothesis. The small-scale instabilities here correspond to classical Rayleigh-Bénard instabilities that develop when the upper cold boundary becomes gravitationally unstable due to the inverse temperature gradient between the maximum temperature in the shear layer and the upper cold boundary layer. Note that for a strong temperature-dependence of viscosity $(\gamma>10$, see Table 2), a stagnant conductive lid forms, underlying the top cold boundary (Davaille and Jaupart, 1993; 1994). In that case, the instabilities 
of the upper cold boundary layer do not develop over its whole thickness, but beneath the stagnant lid.

Small-scale instabilities, colder than the underlying hot layer, fall and are sheared away by the large-scale flow. Consecutive organization of the flow due to the interaction between both convective scales leads to the formation of a small-scale convective pattern, which organizes under two different morphologies. The further description is based on the combined analysis of isotherms positions, temperature series and Particle Image Velocimetry (PIV) computation in both planes perpendicular and parallel to the hot lateral wall.

Figure 8 displays the two small-scale convective patterns reported in our experiments. When the shear is large enough to balance the falling instability velocity, the dripping instabilities organize into a 2D structure, under the form of stationary rolls (Figures $7 \mathrm{a}, \mathrm{b}$ and 8a). Isotherms do not show the signature of any plume-shaped instability in a plane perpendicular to the heated vertical boundary (Figure 7a) and their positions do not fluctuate in time. A single fluid particle follows an helicoidal path, with axis parallel to the large-scale motion. The vertical extension of the velocity field associated with these instabilities, coupled with observation of dye injection in some experiments, shows that the small-scale pattern remains trapped in the shear zone. Longitudinal rolls are therefore observed, with axis parallel to the large-scale flow, and confined in the shear layer. When the large-scale motion is not strong enough to balance the velocity of the falling instabilities, we observe 3D time-dependent structures: small 'drips' that sink from the cold plate and are driven away by the large-scale flow (Figures $8 \mathrm{~b}, \mathrm{c}$ ). Our results also show that the lateral spacing of the cold drips in the direction perpendicular to the plate velocity, $\lambda$, scales with the thickness of the sheared layer underneath the lithosphere, $d_{\text {shear }}$ (Figure 8d) as

$\lambda=\delta_{\text {shear }}$.

The next section discusses the experimental results in regards to the observations based on the tomography model.

\section{Discussion}

Using three tomography models [SEMUCB-WM1 (French and Romanowicz, 2014), 3D2018_08Sv (Debayle et al., 2016) and Isse2018 Isse et al. (2018)] we identified regions in the Pacific plate associated with abnormally thick lithosphere. The anomalous regions identified with the SEMUCB-WM1 and 3D2018_08Sv models are elongated along the direction of the presentday Pacific plate motion (Figure 2). Correlation with seafloor age shows that these lithospheric anomalies occur in seafloor older than 100-120 Ma, but there is no clear correlation between the anomaly patterns and age distribution of the crust. Consistent with the experimental models presented (Figs. 7 and 8), we interpret these features as lithospheric 'drips'. The lithospheric drips are not correlated with volcanic features but seem to correlate with the locations of bathymetric lows. The long wavelength component of the bathymetric lows is recovered by the dynamic topography computed from the SEMUCB-WM1 and 3D2018_08Sv models and is created by downwelling flow induced by the lithospheric drips. The LAB computed from the 3D2018_08Sv and Isse 2018 models show anomalies that are "smeared" along the direction perpendicular to the 
of the present-day motion of the Pacific plate. This is in agreement with the experimental results, as the lithosphere appears to destabilize at a constant distance from the mid-oceanic ridge.

Our study can be compared to the in-situ measurements of broadband dispersion made by Takeo et al. (2018), who conducted surveys in the northwestern Pacific Ocean by deploying broadband ocean bottom seismometers. They chose two target areas, represented by the white and red boxes reported on the maps of our LAB estimates in Figure 9. The authors compute the azimuthally anisotropic $\beta \mathrm{v}$ by inverting dispersion curves of Rayleigh waves. They find that $\beta \mathrm{v}$ is $2 \%$ lower in the northwestern region (region $\mathrm{A}$ ) relative to the southeastern region (region $\mathrm{B}$ ), indicating that region B is cooler than region A. Similar variations are also found from electrical conductivity profiles (Baba et al., 2017), as the low conductivity layer, typically associated with the lithosphere, is thicker in region B than in region A. These variations are similar to the ones found in this study. Indeed, region B is associated with a thicker lithosphere, while region A is located in an area of "normal" lithosphere, whatever the considered tomography model (see Figure 9 for a visual comparison). More precisely, we find that the mean LAB depth is 105, 97, and $102 \mathrm{~km}$ over region A, according to the SEMUCB-WM, 3D2018_08Sv and Isse2018 models respectively. Over region $\mathrm{B}$, the depth of the LAB is 113,119 , and $146 \mathrm{~km}$, according to the SEMUCB-WM, 3D2018_08Sv and Isse 2018 models, respectively.

Takeo et al. (2018) argue that such variations cannot be accounted for by differences in seafloor age, or by the presence of volcanic features such as the Shatsky Ridge. They conclude that their in situ measurements indicate "the first evidence for the occurrence of SSC beneath the old northwest Pacific Ocean". The results of Takeo et al. (2018) are groundbreaking and essential for constraining the location of SSC beneath oceanic plates, but our interpretations from this study differ. Takeo et al. (2018) conclude that SSC is occurring beneath region A, as it is associated with a thinner lithosphere. We propose SSC is mainly occurring beneath region B. Clearly, the effects of SSC and its signature in geophysical observations are not well constrained. This points out the importance of considering jointly geophysical data (seismic models in particular), and laboratory experiments.

Laboratory experiments provide complementary insights into the phenomenology and structure of small-scale convection. In particular, we report the existence of two possible structures: either the instabilities organize into longitudinal rolls, aligned along the direction of the shear flow (or plate motion), or they remain as $3 \mathrm{D}$, time-dependent cold plumes that drip from the base of the lithosphere and are sheared away by the large-scale flow. Figure 10 summarizes the experimental results in a regime diagram. The main parameter governing the transition between the two patterns seems to be the ratio between the vertical velocity of the falling instabilities and the horizontal velocity of the shear flow. We also report in the regime diagram the values derived from the geophysical data. We define $\mathrm{Ra}$ using the same equation as that for the analogical part (equation 3 ), with $\alpha=3.10^{-5} \mathrm{~K}^{-1}, g=9.81 \mathrm{~ms}^{-2}, T_{\text {lat }} T_{u p}=2100 \mathrm{~K}-273 \mathrm{~K}=1827 \mathrm{~K}$ (see Figure S8b and S8), $h=3,000 \mathrm{~km}, \kappa=10^{-6} \mathrm{~m}^{2} \mathrm{~s}^{-1}$. We vary the viscosity of the lithosphere between $10^{20}$ and $10^{24} \mathrm{Pas}$, as suggested by previous publications (Lev and Hager, 2008; Yoshida et al, 2010). The density of the oceanic lithosphere also varies between 2700 and $2900 \mathrm{~kg} \mathrm{~m}^{-3}$ (Turcotte and Schubert, 1982). The derived $\mathrm{Ra}$ varies between $3.9 \times 10^{5}$ and $4.2 \times 10^{7}$. The ratio $\mathrm{v}_{\text {instab }} / \mathrm{v}_{\text {shear }}$ is not a direct observation, and, therefore, depends on the model parameters, such as the viscosity and the conversion law between seismic velocities anomalies. 
In geodynamic studies, the viscosity is often assumed to be depth or temperature dependent. Here we illustrate the effect of the viscosity on the $v_{\text {instab }} / v_{\text {shear }}$ ratio. We consider the effect of the temperature-dependent viscosity on the mantle convection using an Arrhenius-type viscosity form $\eta^{*}=\eta(d)^{*} \exp \left(\frac{H_{a}^{*}}{R^{*} T^{*}}-\frac{H_{a}^{*}}{R^{*} T_{r e f}^{*}}\right)$

where $H_{a} *$ is the activation enthalpy of mantle rock, $R *$ is the gas constant $\left(8.31 \mathrm{~kJ} \mathrm{~mol}^{-1}\right), T^{*}$ and $T_{r e f} *$ are the temperature and reference temperature, respectively (asterisks denote the values with dimension). Eq. (11) is non-dimensionalized by:

$\eta=\eta_{r e f}(d) \exp \left(\frac{H_{a}}{T}-\frac{H_{a}}{T_{\text {ref }}}\right)$

$T$ and $T_{r e f}$ are the dimensionless temperature and reference temperature, respectively, and $\eta_{r e f}(d)$ is the dimensionless reference viscosity at $T=T_{r e f}$. When $T_{r e f}$ is fixed at $0.5, T$ can be expressed as:

$T=T_{\text {ref }}-\gamma \delta \ln (v)=0.5-\gamma \delta \ln (13)$

where $\gamma$ is the dimensionless coefficient defined as:

$\gamma \equiv \frac{0.5}{A_{V T} T_{r e f}^{*}}(14)$

We consider $H a=400 \mathrm{~kJ} \mathrm{~mol}^{-1}$, in the upper mantle and the lower mantle. For the lower mantle we use this value following the study of by Yamasaki and Karato (2001). This temperature dependency has successfully been used in previous studies (Adam et al., 2014; 2015).

The relative viscosity obtained through this law is represented in Figure 11a, a transect located at at latitude $20^{\circ} \mathrm{N}$. The lithosphere appears as a viscous layer $\left(\eta=10^{23} \mathrm{~Pa}\right.$ s), while the asthenosphere has a low viscosity $\left(\eta=10^{19} \mathrm{~Pa} \mathrm{~s}\right)$. We also consider viscosities that are only depth dependent. The depth dependency is illustrated by the red profile in Figure $11 \mathrm{~b}$, which includes a high viscosity lithosphere $\left(\eta=10^{23} \mathrm{~Pa} \mathrm{~s}\right)$, a low viscosity asthenosphere $\left(\eta=10^{19} \mathrm{Pas}\right)$, and a lower mantle that is 30 times more viscous than the upper mantle $\left(\eta=3 \times 10^{21}\right.$ Pas $)$. The blue profile shows the temperature dependent viscosity at the location $20^{\circ} \mathrm{N}, 180^{\circ} \mathrm{E}$. The green profile shows a depth and temperature dependent viscosity at the same location. In this case, the temperature dependency is the one previously described, and the depth dependency includes an upper mantle $\left(\eta=10^{21}\right.$ Pas) and a lower mantle $\left(\eta=3 \times 10^{21} \mathrm{Pas}\right)$, as the lithosphere and asthenosphere viscosity variations are well taken into account by the temperature dependency (Figure 11a).

The $\mathrm{v}_{\text {instab }} / \mathrm{v}_{\text {shear }}$ ratio obtained with these viscosities are reported in panels $\mathrm{c}, \mathrm{d}$, and e. We consider these ratios in the contours located between longitudes 160 and $220^{\circ} \mathrm{W}$, as near longitude $140^{\circ} \mathrm{W}$ there is a subduction zone that perturbs the interaction between the lithosphere and asthenosphere we are studying. The $\mathrm{V}_{\text {instab }} / \mathrm{v}_{\text {shear }}$ ratio is about 0.01 for a depth-dependent viscosity (panel c), 0.5 for a temperature-dependent viscosity (panel d), and 1 for a depth and temperature dependent viscosity (panel e). The $\mathrm{v}_{\text {instab }} / \mathrm{v}_{\text {shear }}$ ratio varies then between 0.01 and 1 . This ratio has been computed for only three viscosity laws, which may be a matter of debate. Numerous laws have been published (e.g. Panasyuk and Hager 2000; Soldati et al. 2009; Höink et al., 2012; Noack and Breuer, 2013; Rudolph et al. 2015, among numerous others). However, it is actually not very clear which laws are more realistic, as pointed out in the review paper by King (2016). 
In Figure 10 the blue box represents the ranges defined by the parameters retrieved from geophysical data and models, as discussed above. It encompasses most of the area defined from the laboratory experiments. Therefore, according to the regime diagram, we find that in the "real Earth", steady rolls and 3D cold plumes convective patterns can coexist, depending on the plate velocity and on the mantle rheology structure, as already proposed by Korenaga and Jordan (2004).

The lithospheric instabilities determined from the tomography show discontinuous elongated patterns parallel to the Pacific plate motion (Figure 1). This suggests that the secondary convection below the North Pacific occurs as sinking cold plumes or drips falling from the base of the lithosphere and sheared away by the large-scale flow, in contrast to steady Richter rolls. Our experimental study (Figure 10) predicts that this indeed can happen for velocity ratios that exceed 0.1 . This range of velocity ratios is in agreement with what is predicted for the mantle temperaturedependent or temperature-and-pressure dependent viscosities (Figures11d-e). Moreover, the laboratory experiments show that the lateral spacing of the cold drips in the direction perpendicular to the plate velocity scales with the thickness of the sheared layer underneath the lithosphere (Figure 8d). Therefore, if small-scale convection remains trapped within the asthenosphere, this would give drips and/or rolls spacings of about $150 \mathrm{~km}$, in agreement with some 3D numerical studies (e.g. Balmer et al, 2007) and some of the gravity wavelengths observed close to ridges (e.g. Wessel et al, 1994). On the other hand, a spacing of $1000 \mathrm{~km}$ implies that the shear induced by the Pacific plate velocity extends down to $1000 \mathrm{~km}$ (cf. Figure 8d), i.e. deeper than the $660 \mathrm{~km}$ phase transition. This would suggest that this phase transition is not sufficient to arrest downwelling drips from the lithosphere (Korenaga and Jordan, 2004). Alternatively, it has been shown that anisotropic viscosity can significantly increase the wavelength of instabilities, while not affecting their depth (Lev and Hager, 2008). Therefore, small-scale instabilities with wavelengths of 1,000 $\mathrm{km}$ could still be confined in the asthenosphere (Ballmer, 2017).

It might sound awkward to name the cold dripping instabilities from the lithosphere "small-scale convection" when their spacing reaches $1000 \mathrm{~km}$, and Ballmer (2017) prefers to call them "midscale convection patterns", reserving the "small-scale convection" terminology for the smaller 100-200 km spacing. However, it should be emphasized that both spacing, whatever their names, can be produced by the same phenomenon: gravitational instabilities from the bottom of a moving lithosphere.

The present work therefore confirms the existence of a "mid-scale convection"- or small-scale convection with about $1000 \mathrm{~km}$ wavelength - already suggested by previous studies (Katzman et al., 1998; Korenaga and Jordan, 2004; French et al, 2013). Its precise characterization from the SEMUCB-WM1 seismic tomography correlates well with highly resolved data such as bathymetry and the geoid, making this result significant. This does not discard the possible existence of even smaller scale of convection of about 100-150 km beneath younger lithosphere (e.g. Ballmer, 2017). This "secondary", or maybe we should call it "tertiary", convection cannot be "seen" at present in tomography models, as they do not have enough spatial resolution. Their future development may contribute to bring more answers to this debate.

6. Conclusion 
We characterize the base of the lithosphere from three tomography models [SEMUCB-WM1 (French and Romanowicz, 2014), 3D2018_08Sv (Debayle et al., 2016) and Isse2018 (Isse et al. (2018)]. From the SEMUCB-WM1 and 3D2018_08Sv models we identify lithospheric drips, where the lithosphere is several tens of $\mathrm{km}$ thicker than in the surrounding regions. They occur on lithosphere that is $100 \mathrm{Ma}$ and older, but without any clear correlation with the isochrons pattern. The lithospheric anomalies are elongated along the present-day direction of Pacific plate motion. This correlation suggests a link with present-day mantle dynamics, rather than with absolute seafloor age. Laboratory experiments focusing on cold instabilities generated by gravitational destabilization of an upper cold boundary layer, and sheared by large-scale flow, show the existence of two different convective patterns. Either the cold drips organize into longitudinal rolls, aligned in the direction of the large-scale flow or, for higher falling drip velocity or lower shear flow velocity, the instabilities are time-dependent cold 3D-plumes, organizing into helices when sheared by the large-scale convection.

The results obtained for the Pacific plate from geophysical data, and in particular from the tomography models, are consistent with the prediction of the convective regimes obtained experimentally. They show that secondary convection and the induced lithosphere destabilization under the Pacific plate occurs as 3D time-dependent dripping instabilities rather than steady convective rolls.

Figure captions

Figure 1: Lithosphere-asthenosphere boundary. Panels a-i are depth cross sections across tomography models along the profiles reported in panels $\mathrm{j}-1$. Panels a-c show depth cross sections across the SEMUCB-WM1 tomography model (French and Romanowicz, 2014), panels d-f across the 3D2018_08Sv model (Debayle et al., 2016), and panels g-i across the Isse2018 model (Isse et al., 2018). The white line is our approximation of the base of the lithosphere. $\mathrm{j}-1$ Maps of the depth to the base of the lithosphere for the different considered tomography models, and locations of the AA', BB', and CC' profiles. m-o zoom in maps of the LAB. p) depth to the maximal anisotropy computed from the Isse 2018 model. In panels $\mathrm{m}-\mathrm{p}$, the black thick lines are plates boundaries, taken from Bird (2003). The profiles AA' and BB' are flow lines, representative of the present-day motion of the Pacific plate, taken from Adam et al. (2015), computed from the Nuvel1A model in the HS3 reference frame (Gripp and Gordon, 2002). The CC' profile is perpendicular to the flow lines.

Figure 2: Age of the seafloor (data from Müller et al., 2008) and contours of the depth to the base of the lithosphere according to the SEMUCB-WM1 tomography model (a), to the 3D2018_08Sv model (b) and to the Isse2018 model (c). The red and white lines represent the 120 and $150 \mathrm{~km}$ depths respectively, for the SEMUCB-WM1 and 3D2018_08Sv models. For the Isse2018 model, the red and white lines represent the 120 and $130 \mathrm{~km}$ depths, respectively. The white arrows 
show the present-day direction of Pacific plate motion [Nuvel1A model in the HS3 reference frame (Gripp and Gordon, 2002)]. The black thick lines represent plate boundaries, taken from Bird (2003).

Figure 3: Correlation between the lithospheric instabilities and volcanic features. a) Bathymetry map (data from Becker et al., 2009) and names of the main topographic features. The names of the volcanic chains are reported in red. The names of the oceanic plateaus are reported in black. The red stars are active hotspots taken from King and Adam (2014). Acronyms for the volcanic features: PS - Petit Spot Volcanism, LI - Line Islands, L - Louisville, OJP - Ontong Java Plateau, MPM - Mid-Pacific Mountains, HR - Hess Rise, SR - Shatsky Rise and MW- MarkusWake seamounts. In panels b-d we display the bathymetry over the northwest Pacific plate, and report isovalues of the depth to the base of the lithosphere determined with SEMUCB-WM1 (b), 3D2018_08Sv (c), and Isse2018 (d). The 120 and $150 \mathrm{~km}$ isovalues are reported in red and white, respectively, at the exception of panel c, where the red line represents the $130 \mathrm{~km}$ isovalue. The black thick lines represent plate boundaries, taken from Bird (2003). The green lines AA' and BB' are profiles along which we investigate the structure of the mantle and the lithosphere. e-j Depth cross sections across the tomography models along the trajectories AA' and BB' reported in panels a-d. The names of the plumes and of the tomography models are reported in each panel. The white line is our approximation of the base of the lithosphere.

Figure 4: Dynamic topography and convection flow. a) Bathymetry (data from Becker et al., 2009); b) filtered bathymetry (see text for details). c-f dynamic topography computed from the SEMUCB-WM1(c), 3D2018_08Sv (d) plate (e), and half space (f) models. The black thick lines represent plate boundaries, taken from Bird (2003). The red stars are active hotspots taken from King and Adam (2014). The green line is the AA' profile along which we investigate the dynamic topography and bathymetry correlations. g-i correlation between the bathymetry (black line) and the dynamic topography computed from the considered models (legend in the panels). The dynamic topographies have been shifted down $5,500 \mathrm{~km}$, to allow a visual comparison with the bathymetry. j) Bathymetry (black line) and dynamic topography computed from the SEMUCB-WM1 model (red line) interpolated along the AA' profile. The dynamic topography is shifted down 5,500 km to be at the same level as the bathymetry. $\mathrm{k}$ ) Depth cross sections showing the structure of the mantle and lithosphere provided by the SEMUCB-WM1 tomography model along the AA' profile. The arrows represent the flow pattern induced by the density anomalies derived from the tomography model (norm $\sim \mathrm{mm} \mathrm{yr}^{-1}$ ). The colored stars delimit regions of abnormally thick lithosphere along the AA' profile (panel c).

Figure 5: Geoid anomalies. Observed geoid (EGM2008, Pavlis et al., 2012) for $1=10-40$ (a) and l=14-39 (b). Geoid anomaly computed from the SEMUCB-WM1 tomography model for 1=10-40 (c) and l=14-39 (d). The black lines represent plate boundaries, taken from Bird (2003). The 120 and $150 \mathrm{~km}$ iso-values of the depth to the base of the lithosphere are reported in red and white, respectively.

Figure 6: Experimental setup. A large-scale flow is forced by a lateral heating at temperature $T_{\text {lat }}$, while the upper and lower walls are cooled at constant temperature $T_{\text {up }} \approx T_{\text {low }}$. The solid black line inside the tank symbolizes the upper cold boundary layer. The laser light sheet can be 
set up horizontally or vertically, and either parallel or perpendicular to the hot plate, for isotherms visualization. Temperature control and measurements of the plates and inside the fluid, respectively, are performed with thermocouple probes. 'REF' indicates the reference point $(x=y$ $=z=0)$.

Figure 7: (a) Temperature field visualized with the four isotherms $\left(10^{\circ} \mathrm{C}, 24^{\circ} \mathrm{C}, 31^{\circ} \mathrm{C}\right.$ and $\left.40^{\circ} \mathrm{C}\right)$ for experiment SG1.1. $T_{\text {lat }}, T_{\text {up }}$ and $T_{\text {low }}$ are the temperatures imposed at the lateral, upper and lower plates respectively. (b) Vertical temperature and horizontal component of the velocity profile for SG2.5 (see Table 6.3), at $x / h=0.78$ and $y / h=0.85$. $\delta_{\text {shear }}$ indicates the shear zone thickness. The horizontal dashed lines indicate the boundaries of different regions: shear zone, linear core, return flow.

Figure 8: Different types of small-scale instabilities developing under the upper cold thermal boundary layer. (a) Stationary structures in experiment SG1.1; the laser plane of light parallel to the hot wall (on background), at a distance $x / h=1.35$. (b) Time-dependent structures in experiment $\mathrm{N} 6$; the laser plane of light is perpendicular to the hot wall (on the right of the image), at a distance $y / h=0.25$. (c) Time-dependent structures in experiment SI1.1; the laser plane of light is parallel to the hot wall (on background), at a distance $x / h=1.15$. (d) Correlation between the lateral spacing of the cold drips in the direction perpendicular to the plate velocity, $\lambda$, and the thickness of the sheared layer underneath the lithosphere, $d_{\text {shear }}$.

Figure 9: Correlation between the LAB assessed in this study and Takeo's et al (2018) in situ measurements. Panels a-c show the depth to the LAB found in the present study from models SEMUCB-WM1(a), 3D2018_08Sv (b), and Isse2018 (c). The red and white boxes show the two target areas along which Takeo et al (2018) performed in situ measurements.

Figure 10: Regime diagram for the different small-scale convective pattern when sheared by the large-scale flow. $v_{\text {instab }} / v_{\text {shear }}$ is the ratio between the vertical velocity of falling instabilities, and the horizontal velocity of the flow. $R a$ is the Rayleigh number defined in Equation 3. In the graph are reported the experimental points. The blue zone represents the possible Earth parameters.

Figure 11: Viscosity laws and $\mathrm{v}_{\text {instab }} / \mathrm{v}_{\text {shear }}$ ratios. a) Viscosity along a depth cross section situated at latitude $20^{\circ} \mathrm{N}$, computed while assuming that the viscosity is only temperature dependent in the upper mantle (logarithmic scale). To allow the convergence of the geodynamic model, we impose minimum and maximum cutoffs for the viscosities of $10^{19}$ Pas and $10^{23}$ Pas. b) Viscosity variations with depth at location $20^{\circ} \mathrm{N}, 180^{\circ} \mathrm{E}$. The red profile illustrates a depth-dependent viscosity, the blue profile a temperature-dependent viscosity, and the green profile a depth- and temperaturedependent viscosity. The $\mathrm{v}_{\text {instab }} / \mathrm{v}_{\text {shear }}$ ratios are displayed in panels $\mathrm{c}, \mathrm{d}$, and $\mathrm{e}$, for viscosities that are purely depth-dependent (panel c), temperature-dependent (panel d), and depth- and temperature-dependent (panel e).

Legend of Tables

Table 1: Physical properties of the fluids: N1 to Nat7.1 indicate the different Natrosol mixtures, SG1 and SG2 the glucose syrups GS6080 and GS6075, respectively, and SI the invert sugar syrup SI9566. $\rho 0, \eta 0$ and $\alpha 0$ are the fluid density, viscosity and thermal expansion coefficient at $20^{\circ} \mathrm{C}$ 
respectively. $\kappa$ is the thermal diffusivity and $\tau_{\text {diff }}$ the characteristic diffusive time (see text for details).

Table 2: List of experiments: $\mathrm{N}$ and Nat indicate Natrosol mixtures, SG glucose syrups and SI inverted sugar syrup. $T_{l a t}, T_{u p}$ and $T_{\text {low }}$ are the temperatures of the lateral, upper and lower plates, respectively. $T_{m}$ is the core temperature (see text). $\gamma=\eta\left(T_{u p}\right) / \eta\left(T_{\text {lat }}\right)$ is the viscosity ratio, $R a_{\text {lat }}$ the lateral Rayleigh number and $\operatorname{Pr}$ the Prandtl number. Symbol * indicates the imposed temperature (no temperature measurements were available for experiments N1 to N6 and SI1.3). Other (measured) temperatures are known within $0.05^{\circ} \mathrm{C}$.

\section{Acknowledgments:}

The comments by Jun Korenaga and an anonymous reviewer helped improve the original manuscript. Datasets for this research are available in this in-text data citation reference: French and Romanowicz (2014), Debayle et al., (2016) and Isse et al. (2018). The model published by Debayle et al., (2016) can be found on this IRIS website https://ds.iris.edu/ds/products/emcearthmodels/. Datasets obtained from this research are included in this paper.

\section{References:}

Adam, C., Vidal, V., Bonneville, A., (2005). MiFil: a method to characterize hotspot swells with application to the South Central Pacific. Geochem. Geophys. Geosyst. 6, Q01003. http://dx.doi.org/10.1029/2004GC000814.

Adam C., M., Yoshida, T., Isse, D., Suetsugu, Y., Fukao, and G., Barruol (2010). South Pacific hotspot swells dynamically supported by mantle flows. Geophys. Res. Lett. VOL. 37 , L08302, doi:10.1029/2010GL042534

Adam C., M. Yoshida, D. Suetsugu, Y. Fukao, and C. Cadio (2014). Geodynamic modeling of the South Pacific Superswell, Physics of the Earth and Planet. Int., 229, 24-39

Adam C., King, S. D., Vidal, V., Rabinowicz, M., Jalobeanu, A., and Yoshida, M. (2015). Variation of the subsidence parameters, effective thermal conductivity, and mantle dynamics, Earth Planet. Sci. Lett., 426, 130-142

Adam, C., M. J. Caddick, and S. D. King (2017). Pyroxenite causes fat plumes and stagnant slabs, Geophys. Res. Lett., 44, 4730-4737, doi:10.1002/ 2017GL072943. 
Auer, L., L. Boschi, T. W. Becker, T. Nissen-Meyer, and D. Giardini (2014). Savani: A variable resolution whole-mantle model of anisotropic shear velocity variations based on multiple data sets. J. Geophys. Res., 119, 3006-3034, doi:10.1002/2013JB010773.

Baba, K., Tada, N., Matsuno, T., Liang, P., Li, R., Zhang, L., et al. (2017). Electrical conductivity of old oceanic mantle in the northwestern Pacific I: 1-D profiles suggesting differences in thermal structure not predictable from a plate cooling model. Earth, Planets and Space, 69(1), 111. https://doi.org/10.1186/s40623-017-0697-0

Ballmer, M. D., J. van Hunen, G. Ito, P. J. Tackley, and T. A. Bianco (2007). Non-hotspot volcano chains originating from small-scale sublithospheric convection, Geophys. Res. Lett., 34(23), doi:doi:10.1029/2007GL031636.

Ballmer, M.D. (2017). Small-scale convection in the Earth's mantle. In: Reference Module in Earth and Environmental Sciences.

Becker, J.J., Sandwell, D.T., Smith, W.H.F., Braud, J., Binder, B., Depner, J., Fabre, D., Factor, J., Ingalls, S., Kim, S.-H., Ladner, R., Marks, K., Nelson, S., Pharaoh, A., Shar- man, G., Trimmer, R., VonRosenburg, J., Wallace, G., Weatherall, P., (2009). Global bathymetry and elevation data at 30 arc seconds resolution: SRTM30_PLUS. Mar. Geod. 32 (4), $355-371$.

Bird, P., 2003. An updated digital model of plate boundaries. Geochem. Geophys. Geosyst. 4 (3), 1027.

Bejan, A., A. Al-Homoud, and J. Imberger (1981). Experimental study of high-Rayleigh-number convection in a horizontal cavity with different end temperature, J. Fluid. Mech., 109, 283-299

Bodine, J., Steckler, M., et Watts, A. (1981). Observations of flexure and rheology of the oceanic lithosphere. J. Geophys. Res., 86, 3695-3707

Buck, W. R., and E. M. Parmentier (1986). Convection beneath young oceanic lithosphere: Implications for thermal structure and gravity, J. Geophys. Res., 91(B2), 1961-1974.

Busse, F., and J. Whitehead (1974). Oscillatory and collective instabilities in large Prandtl number convection. J. Fluid Mech., 66, 67-79

Cazenave, A., K. Dominh, M. Rabinowicz, and G. Ceuleneer (1988). Geoid and Depth 
Anomalies Over Ocean Swells and Troughs - Evidence Of an Increasing Trend Of the Geoid to Depth Ratio With Age Of Plate, Journal Of Geophysical Research Solid Earth and Planets, 93(B7), 8064-8077.

Cazenave, A., Houry, S., Lago, B., and Dominh, K. (1992). Geosat-derived geoid anomalies at medium wavelength. J. Geophys. Res., 97, 7081-7096.

Christensen, U. R., and D. A. Yuen (1989). Time-dependent convection with non Newtonian viscosity, J. Geophys. Res., 94, 814-820

Clouard V. and Bonneville A., Ages of Seamounts Islands and Plateaus on the Pacific P1ate, in Foulger G. R., Natland J.H. Presnall D. C., and Anderson D. L. (2005). Plates, Plumes and Paradigms, Geological Society of America Special Papers vol. 388, 71-90.

Crambes, C. (2002). Deux approches du processus de fusion A- Etude expérimentale de la fusion d'un bloc de solide sous une géométrie verticale B- Etude du volcanisme tibétain, Ph.D. thesis, Institut de Physique du Globe, Paris, 260 p.

Crosby, A. G., D. McKenzie, and J. G. Sclater (2006). The relationship between depth, age and gravity in the oceans, Geophys. J. Int., 166(2), 553-573, doi:10.1111/j.1365246X.2006.03015.x.

Crough, S. T. (1983). Hotspot Swells. Annual Review of Earth and Planetary Sciences, 11(1), 165-193. doi: 10.1146/annurev.ea.11.050183.001121

Curlet, N. (1976). Experimental and numerical modeling of three-dimensional natural convection in an enclosure, Ph.D. thesis, Massachusetts Institute of Technology, Cambridge, 1976

Davaille, A., and C. Jaupart (1993). Transient high-Rayleigh-number thermal convection with large viscosity variations, J. Fluid Mech., 253, 141-166

Davaille, A., and C. Jaupart (1994). Onset of thermal convection in flu- ids with temperaturedependent viscosity: Application to the oceanic mantle, J. Geophys. Res., 99, 19,85319,866

Davaille, A., (1999). Two-layer thermal convection in miscible fluids, J. Fluid Mech., 379, $223-$ 253

Davaille, A., S. Androvandi, J. Vatteville, A. Limare, V. Vidal, and M, Le Bars (2008). Thermal boundary layer instabilities in viscous fluids, ISFV13 - 13th International Symposium on 
Flow Visualization, July 1-4, 2008, Nice, France, 317, 12 p., 2008.

Davies G. (1988). Ocean bathymetry and mantle convection, 1, Large scale flow and hotspots, J. Geophys. Res. , 93 (B9), 10467-10480

Davies, G. F., and Richards, M. A., (1992). Mantle convection. J. Geol. 100, 151-206

Davies, J. H., and Davies, D. R. (2010). Earth's surface heat flux. Solid Earth, 1, 5-24. https://doi.org/10.5194/sed-1-1-2009

Davis, E.E., C.R.B. Lister, and J.G. Sclater, (1984). Towards determining the thermal state of old oceanic lithosphere heat flow measurements from the Blake-Bahama outer ridge, north-western Atlantic, Geophys. J. R. Astron. Soc., 78, 507-545

Davis, E.E., and Lister, C.R.B., (1974). Fundamentals of ridge crest topography, Earth Planet. Sci. Lett., v. 21, p. 405-413, doi:10.1016/0012-821X(74)90180-0.

Debayle, E. and Ricard, Y. (2012). A global shear velocity model of the upper mantle from fundamental and higher Rayleigh mode measurements, J. geophys. Res., 117(B10), doi:10.1029/2012JB009288.

Debayle, E., F. Dubuffet, and S. Durand (2016), An automatically updated S-wave model of the upper mantle and the depth extent of azimuthal anisotropy, Geophys. Res. Lett., 43, 674682, doi:10.1002/2015GL067329.

DeLaughter J., S. Stein, C. A. Stein (1999). Extraction of a lithospheric cooling signal from ocean wide geoid data, Earth Planet. Sci. Lett., 174, 173-181

Doin, M. P., and L. Fleitout (1996). Thermal Evolution Of the Oceanic Lithosphere - an Alternative View, Earth Planet. Sci. Lett., 142(1-2), 121-136.

Dumoulin, C., M.-P. Doin, and L. Fleitout (2001). Numerical simulations of the cooling of an oceanic lithosphere above a convective mantle, Phys. Earth Planet. Inter., 125, 45-64

Fleitout, L., and Yuen, D. (1984). Steady state, secondary convection beneath lithos- pheric plates with temperature- and pressure-dependent viscosity. J. Geophys. Res., 89, $9227-$ 9244.

French, S., Lekic, V. and Romanowicz, B. (2013). Waveform tomography reveals channeled flow at the base of the oceanic asthenosphere, Science, 342, 227-230. 
French, S. W. and Romanowicz, B. A. (2014). Whole-mantle radially anisotropic shear velocity structure from spectral-element waveform tomography. Geophys. J. Int. 199, 1303-1327

French, S. W. and B. Romanowicz (2015). Broad plumes Rooted At The Base Of The Earth's Mantle Beneath Major Hotspots, Nature, 525, 95-99

Goetze, C. (1979). Stress and temperature in the bending lithosphere as constrained by experimental rock mechanics. Geophys. J. R. Astr. Soc., 59, 463-478.

Gripp, A.E., Gordon, R.G. (2002). Young tracks of hotspots and current plate velocities. Geophys. J. Int. 150, 321-361.

Hager, B.H., (1983). Global isostatic geoid anomalies for plate and boundary layer models of the lithosphere. Earth Planet. Sci. Lett. 63, 97-109.

Hall, C. E., and E. M. Parmentier (2003). Influence of grain size evolution on convective instability, Geochemistry Geophysics Geosystems, 4, doi:10.1029/2002gc000308.

Haxby, W., and Weissel, J. (1986). Evidence for small-scale mantle convection from SEASAT altimeter data. J. Geophys. Res., 91 (B3), 3507-3520.

Heestand, R.L., Crough, S.T., (1981). The effect of hot spots on the oceanic age-depth relation. J. Geophys. Res. 86, 6107-6114.

Hirth, G., and Kohlstedt, D., (2003), Rheology of the upper mantle and the mantle wedge: A view from the experimentalists, in Eiler, J., ed., Inside the Subduction Factory: American Geophysical Union Geophysical Monograph 38, p. 83-105, doi:10.1029/138GM06.

Höink, T., Lenardic, A. and Richards, M. A., (2012). Depth-dependent viscosity and mantle stress amplification: implications for the role of the asthenosphere in maintaining plate tectonics, Geophys. J. Int., 191, 30- 41, doi:10.1111/j.1365-24X2012.05621.x

Houseman, G., and McKenzie, D. (1982). Numerical experiments on the onset of convective instability in the Earth's mantle. Geophys. J. R. Astr. Soc., 68, 133-164.

Huang, J., and Zhong, S., (2005), Sublithospheric small-scale convection and its implications for the residual topography at old ocean basins and the plate model, J. Geophys. Res., 110, B05404, doi:10.1029/2004JB003153. 
Isacks, B., Olivier, J., et Sykes, L. (1968). Seismology and the new global tectonics. J. Geophys. Res., 73, 5855-5899.

Isse, T., H. Kawakatsu, K. Yoshizawa, A. Takeo, H. Shiobara, H. Sugioka, A. Ito, D. Suetsugu, and D. Reymond (2019), Surface wave tomography for the Pacific Ocean incorpo- rating seafloor seismic observations and plate thermal evolution, Earth Planet. Sci. Lett., 510, $116-130$.

Ito, G., van Keken, P.E. (2007). Hot spots and melting anomalies. Treatise Geophys. 7, 371-435.

Jaupart, C., and B. Parsons, (1985). Convective instabilities in a variabl viscosity fluid cooled from above, Phys. Earth and Planet Inter., 39,14-32,

Karato, S., and Wu, P., (1993), Rheology of the upper mantle: A synthesis: Science, v. 260, p. 771-778, doi:10.1126/science.260.5109.771.

Karato, S.I. (2008). Deformation of Earth Materials: an Introduction to the Rheology of Solid Earth. Cambridge University Press, New York.

Katzman, R., L. Zhao, and T. H. Jordan (1998), High-resolution, two- dimensional vertical tomography of the central Pacific mantle using ScS reverberations and frequencydependent travel times, J. Geophys. Res., 103, 17,933-17,971.

King. S.D., and B. H. Hager (1990). The relationship between plate velocity and trench viscosity in newtonian and power-law subduction calculations, Geophys. Res. Lett., 17, 12, 24092412

King, S.D., Adam, C. (2014). Hotspot swells revisited. Phys. Earth Planet. Inter. 235, 66-83.

King S. D. (2016). Reconciling laboratory and observational models of mantle rheology in geodynamic modelling. Journal of Geodynamics, 100, 33-50

Korenaga, J., and Jordan, T.H., (2002), On 'steady-state' heat flow and the rheology of oceanic mantle: Geophysical Research Letters, v. 29, 2056, doi:10.1029/2002GL016085.

Korenaga, J., and T. H. Jordan (2003), Linear stability analysis of Richter rolls, Geophys. Res. Lett., 30(22), 2157. 
Korenaga, J., and T. H. Jordan (2004), Physics of multiscale convection in Earth's mantle: Evolution of sublithospheric convection, Journal of Geophysical Research-Solid Earth, 109(B1), 1405.

Korenaga, T., and Korenaga, J., (2008). Subsidence of normal oceanic lithosphere, apparent thermal expansivity, and seafloor flattening: Earth and Planetary Science Letters, v. 268, p. 41-51, doi:10.1016/j.eps1.2007.12.022.

Korenaga J. (2009). How does small-scale convection manifest in surface heat flux? Earth Planet. Sci. Lett., 287, pp. 329-332

Korenaga, J., (2015), Seafloor topography and the thermal budget of Earth, in Foulger, G.R., Lustrino, M., and King, S.D., eds., The Interdisciplinary Earth: A Volume in Honor of Don L. Anderson: Geological Society of America Special Paper 514 and American Geophysical Union Special Publication 71, p. 167-185, doi:10.1130/2015.2514(11).

Krishnamurti, R., (1970). On the transition to turbulent convection, J. Fluid Mech., 42, 295-320

Kroenke, L., and Wessel, P. (2003). The effect of a major change in plate motion on hotspot volcanism. EOS Trans., AGU, 84 (46), Fall Meet. Suppl., Abstract F1489-0573.

Lekic', V. and Romanowicz, B., (2011). Inferring upper-mantle structure by full waveform tomography with the spectral element method, Geophys. J.Int., 185, 799-831.

Lev, E., and B. H. Hager (2008). Rayleigh-Taylor instabilities with anisotropic lithospheric viscosity, Geophys. J. Int., 173(3), 806-814, doi:10.1111/j.1365-246X.2008.03731.x.

Limare, A., I. Kumagai, J. Vatteville, and A. Davaille (2008). Thermal plumes visualization : Differential interferometry versus thermochromic liquid crystals, ISFV13 - 13th International Symposium on Flow Visualization, July 1-4, 2008, Nice, France, 318, 12 p., 2008.

Lister, C .R.B., J .G. Sclater, E, .E. Davis, H . Viilinger, and S . Nagihara (1990). Heat flow maintained in ocean basins of great age: Investigations in the north-equatorial west Pacific, Geophys. J. Int., 102, 603-630,1 990.

Marquart, G., H. Schmeling, and A. Braun (1999). Small-scale instabilities below the cooling oceanic lithosphere, Geophys. J. Int., 138, 655-666

Marty, J.C., Cazenave, A., (1989). Regional variations in subsidence rate of oceanic plates: a 
global analysis. Earth Planet. Sci. Lett. 94, 301-315.

McNutt, M., et Menard, H. (1982). Constraints on the yield strenght in oceanic lithosphere derived from observations of flexure. Geophys. J. R. Astr. Soc., 71, 363-394.

McNutt, M. (1984). Lithospheric flexure and thermal anomalies. J. Geophys. Res., 89, 11,18011,194 .

Müller, R.D., Sdrolias, M., Gaina, C., Roest, W.R. (2008). Age, spreading rates, and spreading asymmetry of the world's ocean crust. Geochem. Geophys. Geosyst. 9, Q04006.

Nataf, H.-C., C. Froideveaux, J. Levrat, and M. Rabinowicz (1981). Laboratory convection experiments: effects of lateral cooling and generation of instabilities in the horizontal boundary layers, J. Geophys. Res., 86, 6143-6154

Nishimura, C., et Forsyth, D. (1985). Anomalous Love-wave phase velocity in the Pacific : sequential pure path and spherical harmonic inversion. Geophys. J. R. Astr. Soc., 64, 389-407.

Noack, L., and Breuer, D. (2013). First- and second-order Frank-Kamenetskii approximation applied to temperature-, pressure- and stress-dependent rheology, Geophys. J. Int.,195, 27-46. doi: 10.1093/gji/ggt248

Ogawa, M., G. Schubert, and A. Zebib (1991). Numerical simulations of three dimensional thermal convection in a fluid with strong temperature dependent viscosity. J . Fluid Mech., 233, 299-328

Panasyuk, S. V., and Hager, B. H., (2000). Inversion for mantle viscosity profiles constrained by dynamic topography and the geoid, and their estimated errors, Geophys. J. Int., 143, 821836

Pandit B. (2020), Characterization of secondary mantle convection from geophysical data and models, (Unpublished master's thesis), Kansas State University, Manhattan, Kansas.

Panning, M. and Romanowicz, B. (2006). A three-dimensional radially anisotropic model of shear velocity in the whole mantle, Geophys. J. Int., 167, 361-379.

Parmentier, E. M., D. L. Tircotte, and K. E. Torrance (1976). Studies of Finite Amplitude NonNewtonian Thermal Convection With Application to Convection in the Earth's Mantle, J. Geophys. Res., 81, 11, 1839-1846 
Parsons, B., and J. Sclater (1977). An analysis of the variation of ocean floor bathymetry and heat flow with age, J. Geophys. Res., 82, 803-827

Parsons, B., and McKenzie, D. (1978). Mantle convection and the thermal structure of the plates. J. Geophys. Res., 83 (B9), 4485-4496.

Pavlis, N. K., S. A. Holmes, S. C. Kenyon, and J. K. Factor (2012). The development and evaluation of the Earth Gravitational Model 2008 (EGM2008). J. Geophys. Res., 117, B04406, doi:10.1029/2011JB008916.

Renkin, M. L., and J.G. Sclater, (1988), Depth and age in the North Pacific, J. Geophys. Res., 93, 2919-2935

Richter, F., and Parsons, B. (1975). On the interaction of two scales of convection in the mantle. J. Geophys. Res., 80(17), 2529-2541.

Richter, F., H. Nataf, and S. Daly (1983). Heat transfer and horizon- tally averaged temperature of convection with large viscosity variations, J. Fluid Mech., 129, 173-192

Ritsema J., Deuss, A., van Heijst H.J., Woodhouse, J.H. (2011). S40RTS: a degree-40 shearvelocity model for the mantle from new Rayleigh wave dispersion, teleseismic traveltime and normal-mode splitting function measurements, Geophys. J. Int. doi: 10.1111/j.1365246X.2010.04884.x

Rudolph, M.L., Lekić, V., and Lithgow-Bertelloni, C. (2015). Viscosity jump in Earth's midmantle, Science 350, 1349-1352. http://dx.doi.org/10.1126/science.aad1929

Sandwell, D., and G. Schubert (1980). Geoid height versus age for symmetric spreading ridges. J. Geophys. Res., 85, 7235-7241

Schroeder, W. (1984). The empirical age-depth relation and depth anomalies in the Pacific ocean basin. J. Geophys. Res., 89(B12), 9873-9883.

Schubert, G., Turcotte, D.L., and Olson, P. (2001), Mantle Convection in the Earth and Planets, Cambridge: Cambridge University Press, 10.1017/CB09780511612879

Sclater, J. G. , L. A. Lawyer, and B. Parsons (1975). Comparisons of long wavelength residual elevation and free air gravity anomalies in the North Atlantic and possible implications for the thickness of the lithospheric plate, J. Geophys. Res.., 80, 1031-1052 
Segel, L. (1969). Distant side-walls cause slow amplitude modulation of cellular convection, J. Fluid Mech., 38, 203-224

Simmons, N., Forte, A. and Grand, S. (2006). Constraining mantle flow with seismic and geodynamic data: a joint approach, Earth planet. Sci. Lett., 246, 109-124.

Simmons, N.A., A.M. Forte, L. Boschi, and S.P. Grand (2010). “GyPSuM: A joint tomographic model of mantle density and seismic wave speeds." J. Geophys. Res. 115:B12310. J. Int., 174:195-212.

Sleep, N. H. (1990). Hotspots and mantle plumes: Some phenomenology. Journal of Geophysical Research, 95(B5), 6715. doi: 10.1029/jb095ib05p06715

Soldati, G., Boschi, L., Deschamps, F., Giardini, D., (2009). Inferring radial models of mantle viscosity from gravity (GRACE) data and an evolutionary algorithm. Phys. Earth. Planet. Int. 176, 19- 32 .

Stein, C. S., and Stein, S. (1992). A model for the global variation in oceanic depth and heat flow with lithospheric age. Nature, 359, 123-129 https://doi.org/10.1038/359123a0

Stein, C. A., and S. Stein (1994), Comparison Of Plate and Asthenospheric Flow Models For the Thermal Evolution Of Oceanic Lithosphere, Geophys. Res. Lett., 21(8), 709-712.

Stengel, K.C., D.S. Oliver, and J.R. Booker (1982), Onset of convection in a variable viscosity fluid cooled from above, J . Fluid Mech., 120, 411-431

Styles E., S. Goes, P. van Keken, J. Ritsema, and H. Smith (2011). Synthetic images of dynamically predicted plumes and comparison with a global tomographic model. Earth and Planet. Sci. Lett. 311, 351-363

Tackley, P. J., D. J. Stevenson, G. A. Glatzmaier, and G. Schubert (1993). Effects of an endothermic phase transition at $670 \mathrm{~km}$ depth in a spherical model of convection in the Earth's mantle, Nature, 361, 699-704.

Tait, S., and C. Jaupart, C. (1989). Compositional convection in viscous melts, Nature, 338, $571-574$

Takeo, A., Kawakatsu, H., Isse, T., Nishida, K., Shiobara, H., Sugioka, H., Ito A., and Utada H. (2018).In situ characterization of the lithosphere-asthenosphere system beneath NW 
Pacific Ocean via broadband dispersion survey with two OBS arrays. Geochemistry, Geophysics, Geosystems, 19, 3529-3539. https://doi.org/10.1029/2018GC007588

Turcotte, D., and Schubert, G. (1982). Geodynamics - Applications of continuum physics to geological problems. John Wiley and Sons. (450 p.)

Vidal V., C., Crambes and A., Davaille, (2003). Intermittence des instabilités petite échelle dans la convection de Rayleigh-Bénard forcée par un écoulement cisaillant, Compte-rendus de la 6e Rencontre du Non-Linéaire, Eds. Y. Pomeau \& R. Ribotta, Non-Linéaire Publications, 301-306

van Hunen, J., S. J. Zhong, N. M. Shapiro, and M. H. Ritzwoller (2005). New evidence for dislocation creep from 3-D geodynamic modeling of the Pacific upper mantle structure, Earth Plan. Sci. Lett., 238(1-2), 146-155.

Wessel, P., Kroenke, L., and Bercovici, D. (1996). Pacific Plate motion and undulations in geoid and bathymetry. Earth Planet. Sci. Lett., 140, 53-66.

White, D .B., (1988) The planform and onset of convection with a temperature dependent viscosity. J . Fluid Mech., 191,247-286

Yamazaki, D., Karato, S., 2001. Some mineral physics constraints on the rheology and geothermal structure of Earth's lower mantle. Am. Mineral. 86, 385-391.

Yoshida, M., 2008. Core-mantle boundary topography estimated from numerical simulations of instantaneous mantle flow. Geochem. Geophys. Geosyst. 9, Q07002. http://dx.doi.org/10.1029/2008GC002008.

Yoshida, M. (2010). Preliminary three-dimensional model of mantle convection with deformable, mobile continental lithosphere. Earth Planet. Sci. Lett. 295 (1-2), 205-218. http://dx.doi.org/10.1016

Zaranek, S. E., and Parmentier E. M., (2004), The onset of convection in fluids with strongly temperature-dependent viscosity cooled from above with implications for planetary lithospheres, Earth Planet. Sci. Lett., 224, 371 - 386. 